\title{
Investigation of the Implications of "Haze Special Law" on Air Quality in South Korea
}

\author{
Jian Wang $\mathbb{D}^{1},{ }^{1}$ Junseok Kim $\left(\mathbb{D},{ }^{1}\right.$ and Wei Shao $\mathbb{D D}^{2}$ \\ ${ }^{1}$ Department of Mathematics, Korea University, Seoul 02841, Republic of Korea \\ ${ }^{2}$ Department of Economics, Korea University, Seoul 02841, Republic of Korea \\ Correspondence should be addressed to Wei Shao; shaowei@korea.ac.kr
}

Received 11 October 2019; Revised 24 December 2019; Accepted 19 February 2020; Published 13 March 2020

Academic Editor: Bernhard C. Geiger

Copyright (c) 2020 Jian Wang et al. This is an open access article distributed under the Creative Commons Attribution License, which permits unrestricted use, distribution, and reproduction in any medium, provided the original work is properly cited.

In this work, the air pollution index in three cities (Seoul, Busan, and Daegu) in South Korea was studied using multifractal detrended fluctuation analysis (MF-DFA). Hurst, Renyi, and Holder exponents were used to analyze the characteristics of the concentration time series of $\mathrm{PM}_{2.5}$ and $\mathrm{NO}_{2}$. The results showed that multifractality exists in each season interval and the multifractal degree of $\mathrm{PM}_{2.5}$ is stronger than that of $\mathrm{NO}_{2}$. To investigate the effects of the implementation of the "haze special law" on February 15, 2019, we analyzed the time series of $\mathrm{PM}_{2.5}$ during the time periods from February 15, 2018, to December 16, 2018, and February 15, 2019, to December 16, 2019. We found that the multifractal spectrum width after the implementation of the law was narrower than that before the law for all the cities, which shows that the enactment of the law has played a role in improving the efficiency of air pollution control in South Korea. We also conclude that the major effects of the law will be particularly visible in larger cities. To study the main causes of multifractality, the shuffled and phase-randomized series were analyzed using MFDFA, and the results demonstrated that the fat-tailed distribution resulted in the multifractality of the time series before and after the implementation of the "haze special law" in Seoul and Daegu, whereas long-range correlation resulted in multifractality of the series before and after the implementation of the law in Busan.

\section{Introduction}

With the rapid development of a social economy and the acceleration of industrialization and urbanization, air pollution has gradually become an important problem affecting people's lives and has therefore garnered considerable attention from the public and government. Air pollution is closely related to climate, ecology, and health. Studies have shown that sulfur oxides and nitrogen oxides can cause great harm to the respiratory system, even leading to respiratory failure in severe cases [1]. Therefore, many researchers have started to investigate the atmospheric particulate matters. Many studies have stated that $\mathrm{PM}_{2.5}$ and $\mathrm{NO}_{2}$ are the two major pollutants among various air pollutants [2-6]. Therefore, in this research, we focused on $\mathrm{PM}_{2.5}$ and $\mathrm{NO}_{2}$ and investigated the two pollutants based on the relationship between the air pollution index (API) and different seasons. We also checked whether the implementation of the "haze special law" on February 15, 2019, had an impact on improving the air quality in South Korea using multifractal detrended fluctuation analysis (MF-DFA).

We know that the MF-DFA model can unveil the multifractal properties hidden in nonstationary time series and that multifractality originates from temporal correlations $[7,8]$. Therefore, the multifractal properties of stock markets [9-13], foreign exchange markets [14-16], bitcoin markets [17], atmospheric sciences [18], and phase transitions [19] have been studied previously. Recently, multifractal analysis was used to study the daily air temperature time series [20]. Moreover, MF-DFA is also an efficient method in analyzing the human heart rate time series [21]. Based on the analysis of blood pressure and heart-rate complexity, Gender Castiglioni et al. [22] used the multifractal technique to investigate cardiovascular warning signals. Moreover, MF-DFA has been used in some studies to implement specific image analysis $[23,24]$. 
In recent years, many studies on air pollutants have been conducted and the results suggested that the increased levels of $\mathrm{PM}_{2.5}$ are associated with a higher mortality and some negative effects on the lungs [25]. Although there are many studies on API, few studies have focused on the MF-DFA of the API time series. Through the hourly $\mathrm{PM}_{2.5}$ average concentration time series, Shi et al. [26] analyzed the multifractal nature at four air monitoring stations of Chengdu using MF-DFA. Zhang et al. [27] used the multifractal detrended cross-correlation analysis (MF-DCCA) to analyze the cross-correlations between $\mathrm{PM}_{2.5}$ and meteorological factors. Recently, Zhang et al. [28] analyzed the multifractal characteristics of the $\mathrm{PM}_{2.5}$ time series in Hong Kong using the empirical mode decomposition-based MFDFA method. Multifractal property links between meteorological factors and pollutants in urban and rural areas have been verified by $\mathrm{He}$ [29].

Based on MF-DFA, the variations of multifractal characteristics of pollutants present in different seasons were investigated in this study. The effects of seasonal factors on $\mathrm{PM}_{2.5}$ and $\mathrm{NO}_{2}$ were analyzed, and the seasonal physical changes of $\mathrm{PM}_{2.5}$ and $\mathrm{NO}_{2}$ concentrations were confirmed using multifractality. Additionally, we conducted a multifractal comparison analysis of the effectiveness of air pollution renovation since the enactment of the "haze special law." From this, we can provide a basis for formulating a scientific and effective comprehensive air pollution control policy.

The paper is organized as follows. We briefly outline the procedure of MF-DFA in Section 2. In the next section, we describe the data information. Section 4 illustrates the empirical results. Section 5 concludes the paper.

\section{Methodology}

In this section, we describe the utilization of the MF-DFA [30] to measure the multifractal behavior of haze in all seasons, and the multifractal characteristics of the API time series before and after the implementation of the "haze special law." Kantelhardt summarized the technical details of MF-DFA as follows.

As a time series $X_{i}$ starts from $X_{1}$ to $X_{N}$, where $N$ is the length of the signal, the corresponding summation sequence is constructed by the following integration:

$$
Y(k)=\sum_{i=1}^{k}\left(X_{i}-\bar{X}\right), \quad k=1,2, \ldots, N,
$$

where $\bar{X}$ is the mean value of $X_{i}$.

Subsequently, the profile $Y$ is further divided into $N_{s}$ nonoverlapping windows of equal length $s$. In most cases, the scale $s$ is not a multiple of the time series and a short part at the end of series $Y$ exists. To overcome the problem of information being lost in the division process, the same process is repeated starting from the other side of the series. Thus, $2 N_{s}$ windows are acquired.

Next, the least squares method is used to fit the data for evaluating the local trend of each window $v\left(v=1,2, \ldots, 2 N_{s}\right)$, and the fitting polynomial in the $v_{\text {th }}$ window is denoted by $y_{v}(i)$. The variance is determined by the detrended time series, which is calculated as the difference between $Y$ and $y$, and the resultant equation is described as

$$
F^{2}(s, v)=\frac{1}{s} \sum_{i=1}^{s}\left\{Y[(v-1) s+i]-y_{v}(i)\right\}^{2},
$$

if $v=1,2, \ldots, N_{s}$, and

$$
F^{2}(s, v)=\frac{1}{s} \sum_{i=1}^{s}\left\{Y\left[N-\left(v-N_{s}\right) s+i\right]-y_{v}(i)\right\}^{2}
$$

if $v=N_{s}+1, N_{s}+2, \ldots, 2 N_{s}$.

Finally, computing the mean of $2 N_{s}$ windows, the $q$ order wave function $F_{q}(s)$ is obtained as

$$
F_{q}(s)=\left\{\frac{1}{2 N_{s}} \sum_{v=1}^{2 N_{s}}\left[F^{2}(s, v)\right]^{q / 2}\right\}^{1 / q},
$$

if $q=0$; according to L'Hôpital's rule,

$$
F_{q}(s)=\exp \left\{\frac{1}{2 N_{s}} \sum_{v=1}^{2 N_{s}} \ln \left[F^{2}(s, v)\right]\right\} .
$$

Through the analysis of double log plots of $F_{q}(s)$ versus $s$ and a varied $q$, the scaling behavior of the fluctuation is determined by the power-law $F_{q}(s) \propto s^{h(q)}$, and from this, a family of scaling exponents $h(q)$, which are generalized Hurst components, can be obtained. $F_{q}(s)$ is the standard DFA, if $q=2$. The Hurst exponents provide information on the time series, such as power-law correlated behavior, and when $0<h(q)<0.5$, it indicates that the time series has a negative or antipersistence property. When $0.5<h(q)<1$, then the time series has a positive persistence, and $h(2)=0.5$ indicates that the time series has an uncorrelated Brownian process.

The Renyi exponent $\tau(q)$, which is related to the general Hurst exponent, can be expressed by

$$
\tau(q)=q h(q)-1
$$

In addition,

$$
\begin{gathered}
\alpha=h(q)+q h^{\prime}(q), \\
f(\alpha)=q[\alpha-h(q)]+1,
\end{gathered}
$$

where $\alpha$ represents the Holder exponent and characterizes the singularity strength and $f(\alpha)$ is a fractal dimension of the set of points with particular $\alpha$. In the plotted curve between $\alpha$ and $f(\alpha)$, the shape resembles an inverted parabola and the degree of their complexity is denoted by the width of their fractal strength $\Delta \alpha$ [31].

\section{Data Collection}

We used the API time series of Seoul to study the multifractal characteristics of API sequences in different seasons. To gauge the impact of the implementation of the "haze special law," our data set covered 3 cities in South Korea. The 3 cities are located in different parts of South Korea, and 
TABLE 1: Information of cities in the sample.

\begin{tabular}{lcc}
\hline City & Location & Monitoring station \\
\hline Seoul & Northwest & Jung-gu \\
Busan & Southeast & Gaegeum-do \\
Daegu & Centrum & Guseong-dong \\
\hline
\end{tabular}

TABle 2: Descriptive statistics.

\begin{tabular}{|c|c|c|c|c|c|}
\hline Observation & Observation number & Minimum & Maximum & Mean & Standard deviation \\
\hline Spring $\left(\mathrm{PM}_{2.5}\right)$ & 90 & 18 & 195 & 94.289 & 43.470 \\
\hline Summer $\left(\mathrm{PM}_{2.5}\right)$ & 90 & 13 & 139 & 71.722 & 33.368 \\
\hline Autumn $\left(\mathrm{PM}_{2.5}\right)$ & 90 & 14 & 170 & 67.711 & 36.996 \\
\hline Winter $\left(\mathrm{PM}_{2.5}\right)$ & 90 & 35 & 204 & 102.022 & 33.840 \\
\hline Spring $\left(\mathrm{NO}_{2}\right)$ & 90 & 0.013 & 0.059 & 0.033 & 0.011 \\
\hline Summer $\left(\mathrm{NO}_{2}\right)$ & 90 & 0.008 & 0.039 & 0.024 & 0.007 \\
\hline Autumn $\left(\mathrm{NO}_{2}\right)$ & 90 & 0.009 & 0.066 & 0.031 & 0.012 \\
\hline Winter $\left(\mathrm{NO}_{2}\right)$ & 90 & 0.010 & 0.073 & 0.038 & 0.015 \\
\hline Seoul (before law) & 305 & 13 & 195 & 79.708 & 39.268 \\
\hline Seoul (after law) & 305 & 12 & 210 & 78.498 & 37.907 \\
\hline Busan (before law) & 305 & 42 & 161 & 91.161 & 28.590 \\
\hline Busan (after law) & 305 & 23 & 169 & 84.023 & 26.869 \\
\hline Daegu (before law) & 305 & 25 & 158 & 86.138 & 31.332 \\
\hline Daegu (after law) & 305 & 21 & 168 & 82.902 & 28.525 \\
\hline
\end{tabular}

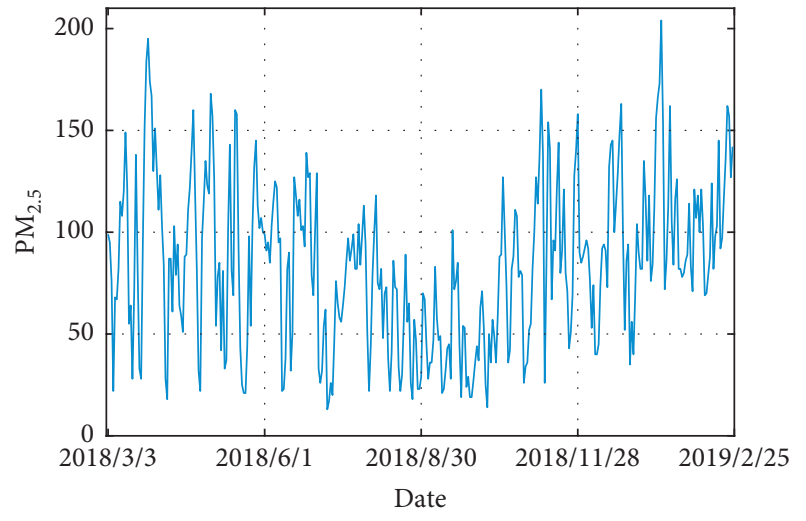

(a)

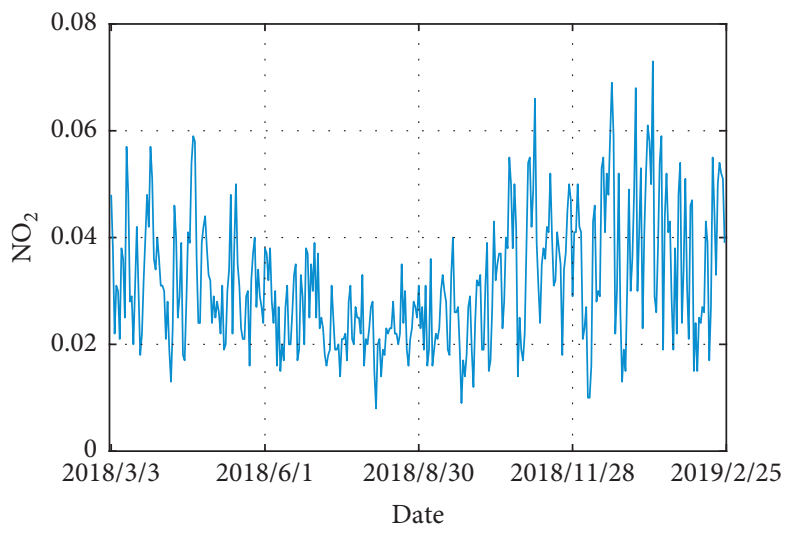

(b)

Figure 1: Time series of (a) $\mathrm{PM}_{2.5}$ concentration and (b) $\mathrm{NO}_{2}$ concentration.

there is a certain distance between any two cities. The results calculated from the samples selected in this manner fully reflect the impact and effect of the implementation of the "haze special law" over the entirety of South Korea.

The experimental data sources for the $\mathrm{PM}_{2.5}\left(\mu \mathrm{g} / \mathrm{m}^{3}\right)$ and $\mathrm{NO}_{2}(\mathrm{ppm})$ concentrations were the "Korean Ministry Of Environment" and "Korea Environment Corporation," and more specific data were provided by the monitoring stations in South Korea. For more detailed information, please refer to https://www.airkorea.or.kr/web and https://aqicn.org/ city/seoul/kr. Table 1 shows information of the target cities and the corresponding monitoring stations. For the multifractal analysis of API in different seasons, the samples were recorded from March 3, 2018, to February 25, 2019. We considered March to May, June to August, September to
November, and December to February as the four seasons: spring, summer, autumn, and winter, respectively. Each interval was assigned a time series of 90 daily data points. For analyzing the efficiency of the implementation of the "haze special law" on February 15, 2019, we selected a time series of $\mathrm{PM}_{2.5}$ over the same period. The data were recorded from February 15, 2018, to December 16, 2018, and from February 15, 2019, to December 16, 2019, and each interval was assigned a time series of 305 daily data points. The descriptive statistics for each time series are shown in Table 2.

\section{Experiment Results}

We first analyze the multifractal properties for two time series of each season and compare the multifractal degree of 

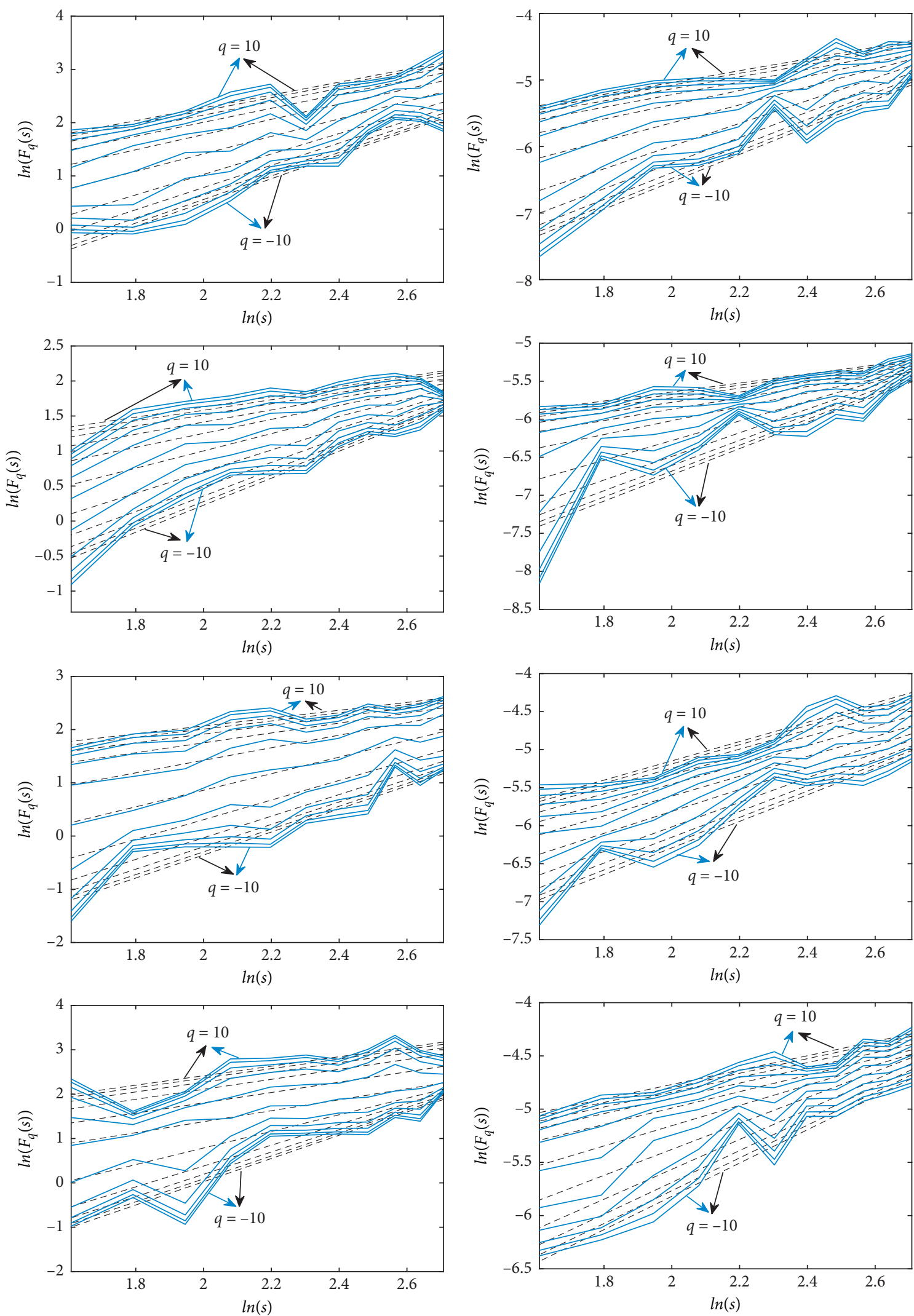

(a)

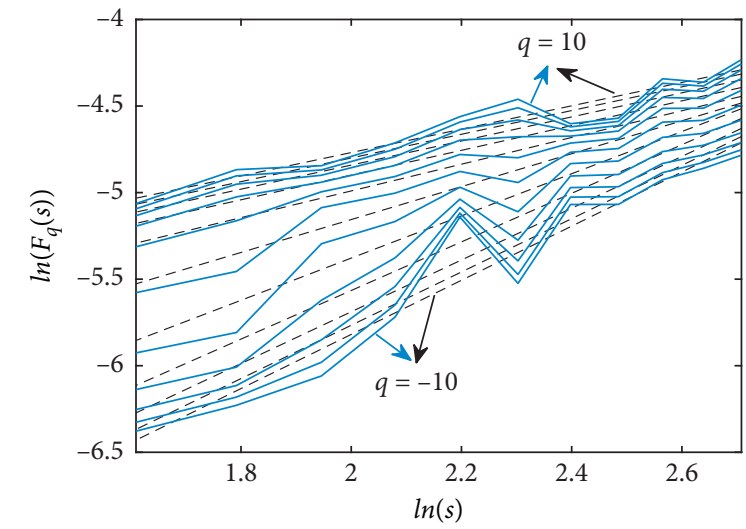

(b)

FIGURe 2: Log-log plots of fluctuation function $F_{q}(s)$ for (a) $\mathrm{PM}_{2.5}$ and (b) $\mathrm{NO}_{2}$. From top to bottom are spring, summer, autumn, and winter. 


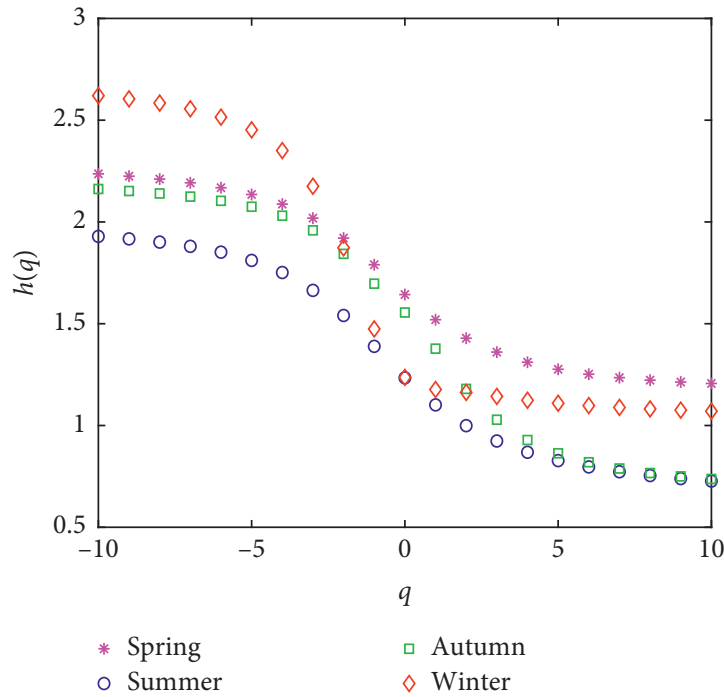

(a)

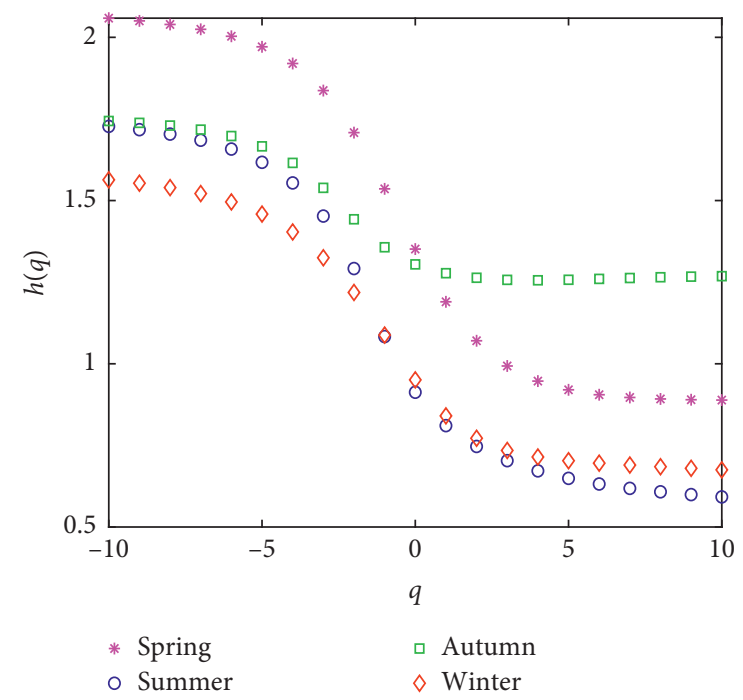

(b)

FIgURE 3: Hurst exponent of (a) $\mathrm{PM}_{2.5}$ concentration and (b) $\mathrm{NO}_{2}$ concentration.

TABLE 3: Multifractality for $\mathrm{PM}_{2.5}$ and $\mathrm{NO}_{2}$ concentrations.

\begin{tabular}{lclll}
\hline & & $h(2)$ & $\Delta H(q)$ & $\Delta \alpha$ \\
\hline & Spring & 1.4290 & 1.0297 & 1.2224 \\
$\mathrm{PM}_{2.5}$ & Summer & 0.9991 & 1.2021 & 1.4787 \\
& Autumn & 1.1797 & 1.4247 & 1.6851 \\
\hline & Winter & 1.1626 & 1.5500 & 2.0520 \\
$\mathrm{NO}_{2}$ & Spring & 1.0705 & 1.1699 & 1.4212 \\
& Summer & 0.7468 & 1.1350 & 1.4151 \\
& Autumn & 1.2635 & 0.4880 & 0.6705 \\
\hline
\end{tabular}

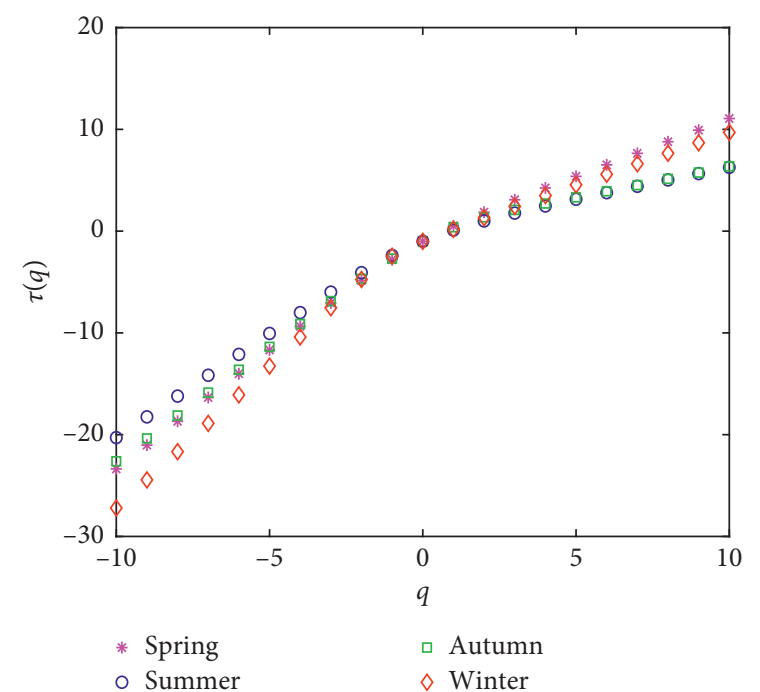

(a)

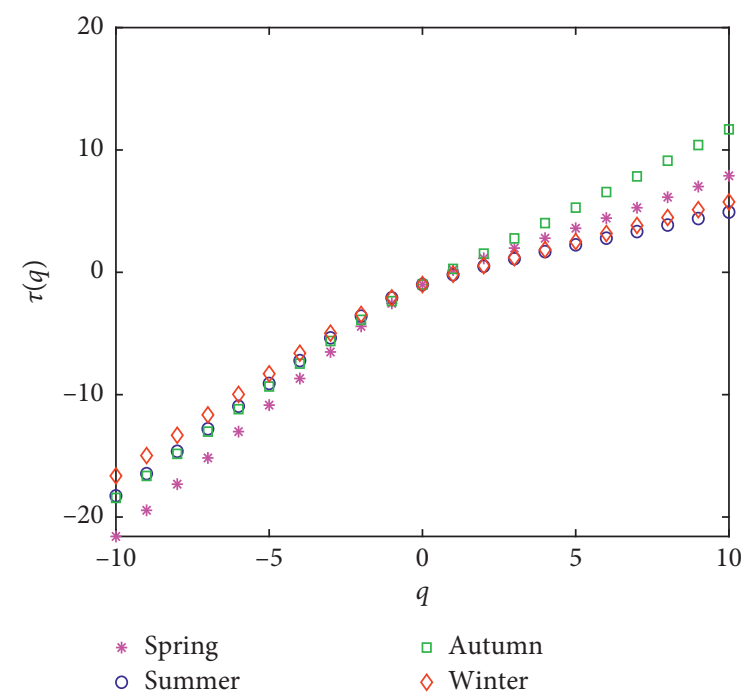

(b)

Figure 4: Renyi exponent of (a) $\mathrm{PM}_{2.5}$ concentration and (b) $\mathrm{NO}_{2}$ concentration. 


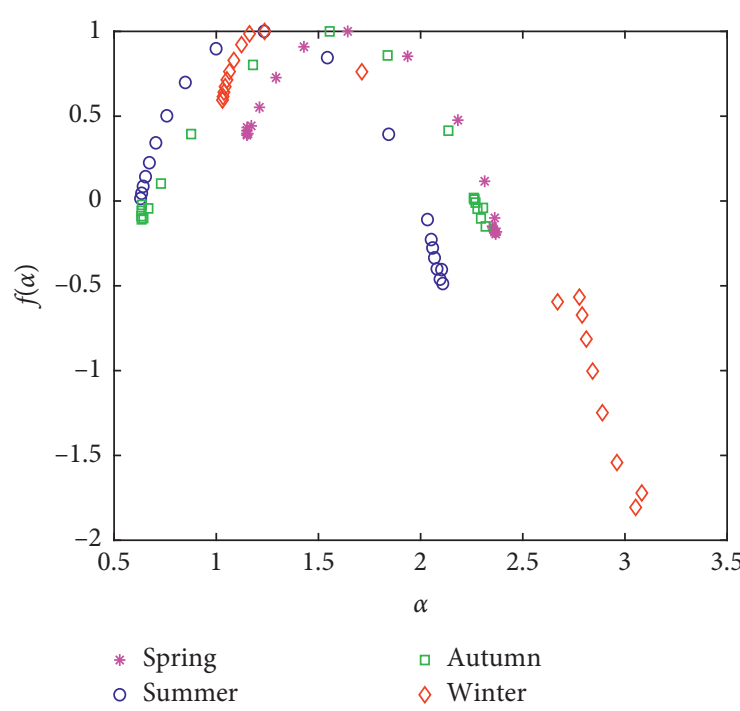

(a)

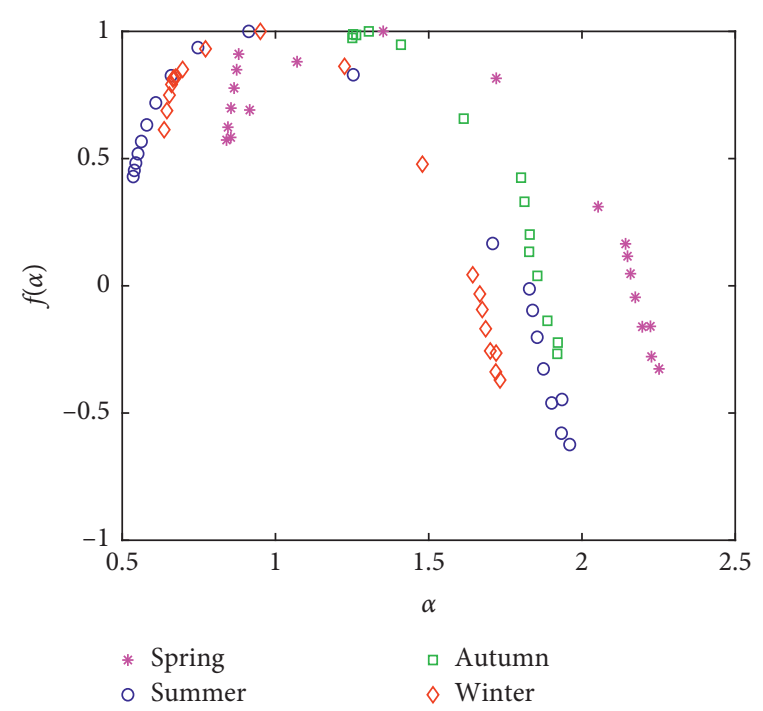

(b)

FIgURE 5: Holder exponent of (a) $\mathrm{PM}_{2.5}$ concentration and (b) $\mathrm{NO}_{2}$ concentration.

$\mathrm{PM}_{2.5}$ with that of $\mathrm{NO}_{2}$. Second, we conduct multifractal analysis for two time series in the same season and confirm whether the implementation of the "haze special law" has any implications for the air quality.

In this study, we choose the minimum segment scale to be $s_{\min }=5$, and the maximum segment scale $s_{\max }=15$, and $q$ is taken from -10 to 10 . The range of $q$ was similarly chosen for the multifractal analysis of stock prices and returns in Latin-American stock markets [32]. Besides, the range of $s$ was selected according to suggestions in $[33,34]$.

4.1. Multifractal Analysis of $\mathrm{PM}_{2.5}$ and $\mathrm{NO}_{2}$. From the daily API data selected in Section 3, we draw the time series of $\mathrm{PM}_{2.5}$ and $\mathrm{NO}_{2}$ in Figure 1. From Figure 1, we can see that a pattern of high concentrations on both sides and low concentrations in the middle emerges, which indicates that due to seasonal factors, both air pollutants have the characteristics of low concentrations in summer and high concentrations in winter. In summer (June to August), the concentration of air pollutants tends to rise, while in winter (December to February of the following year), the concentration of air pollutants tends to decrease.

To check the existence of a scaling range, long-range correlations, and multifractality of both indices in four seasons, we first show the log-log plots of $F_{q}(s)$ versus time scale $s$ of $\mathrm{PM}_{2.5}$ and $\mathrm{NO}_{2}$. In Figure 2, the continuous line represents the double plots between the calculated $F_{q}(s)$ and time scale $s$, and the dashed line denotes the corresponding fitting line. As the dashed line shows, the decreasing gradient with $q$ increases from -10 to 10 , which indicates that $\mathrm{PM}_{2.5}$ and $\mathrm{NO}_{2}$ time series of all seasons have multifractal properties.

To measure the multifractality quantitatively, we apply MF-DFA to estimate properties for two pollutants of indices $\mathrm{PM}_{2.5}$ and $\mathrm{NO}_{2}$. First, we calculate the generalized Hurst exponent $h(q)$ and then obtain the Renyi exponent $\tau(q)$ and the Holder exponent $\alpha$ for both indices.

Figure 3 shows the relationship between $h(q)$ and $q$. The generalized Hurst exponents for both time series in any season are not constants, which indicate that the series are not monofractal. We note that $h(q)$ decreases monotonously with an increase in $q$, which shows that the time series of $\mathrm{PM}_{2.5}$ and $\mathrm{NO}_{2}$ are not single fractals. Figures 3(a) and 3(b) represent $\mathrm{PM}_{2.5}$ and $\mathrm{NO}_{2}$, respectively.

As illustrated in Table 3, the values of $h(2)$ for all time series are larger than 0.5 , implying that the fluctuations have significant positive persistence. Both indices of the time series in some seasons are even larger than 1, which is consistent with the conclusions drawn in some previous studies $[26,35]$. For the $\mathrm{PM}_{2.5}$ time series, the persistence in spring is stronger than for other seasons, and for the $\mathrm{NO}_{2}$ time series, autumn has the strongest persistence. We compute $\Delta H(q)$ for each time series using $\Delta H(q)=h\left(q_{\min }\right)-h\left(q_{\max }\right)$. From Figure 3 and Table 3 , we observe that $\Delta H(q)$ in winter is the highest for the $\mathrm{PM}_{2.5}$ time series, which implies its' multifractal characteristic is stronger in winter, and the multifractalities of the other three seasons are relatively stable. However, for the $\mathrm{NO}_{2}$ time series, the multifractality in spring is higher than for all other seasons.

Furthermore, the multifractality strength of a time series can also be measured with a nonlinear Renyi exponent curve [36]. As shown in Figure 4, all curves of the Renyi exponent are nonlinear, which reflects the evidence of multifractality of the $\mathrm{PM}_{2.5}$ and $\mathrm{NO}_{2}$ series. Moreover, the different nonlinear behaviors of the curves of these series show that the multifractal strengths have different degrees.

Then, we calculate the Holder exponent $\alpha$ and the fractal dimension $f(\alpha)$ using equation (8). The width of $\alpha$ also stands for the degree of the multifractality. A larger $\Delta \alpha$ indicates a stronger multifractal nature. In Figure 5 and 

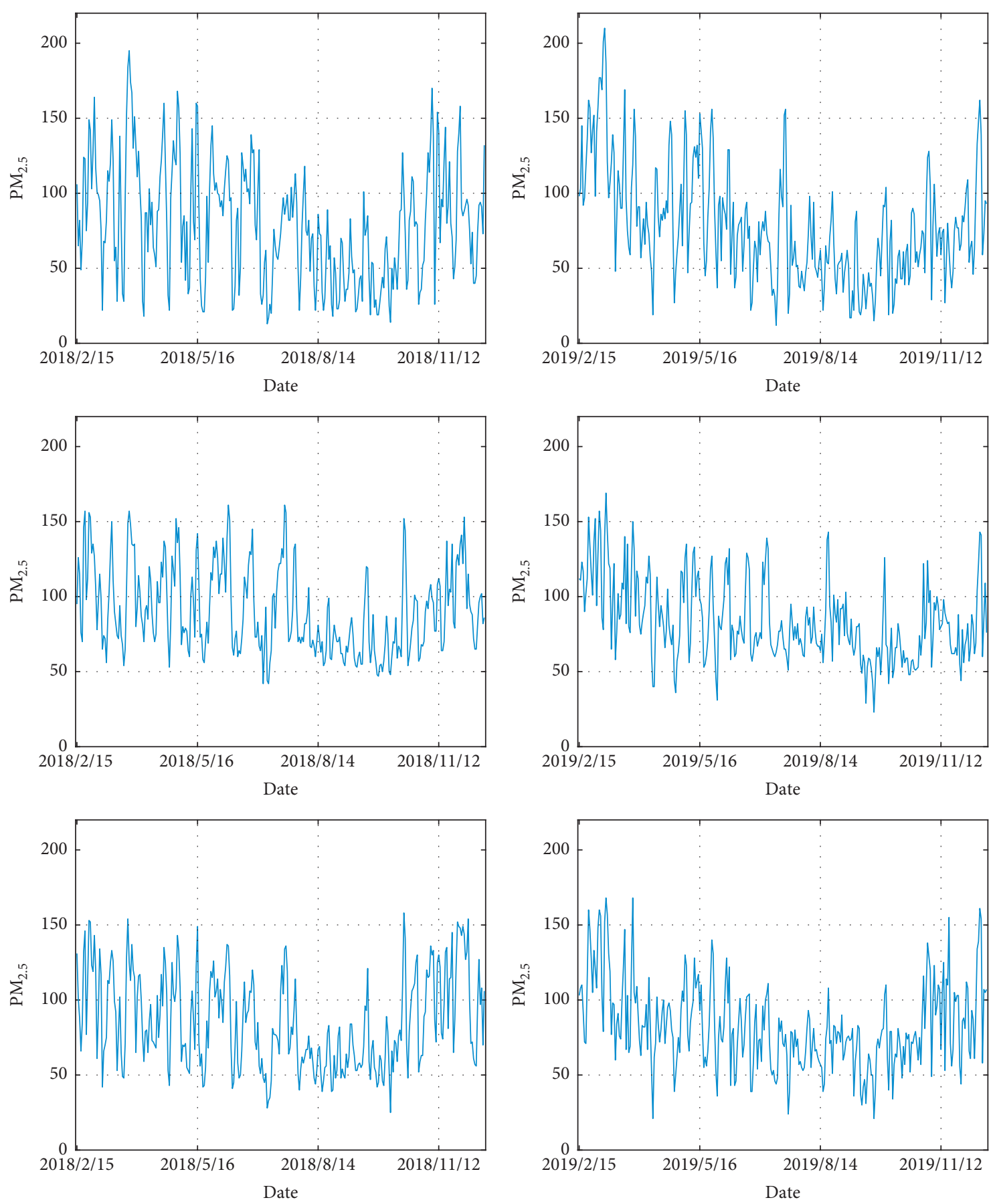

(a)

(b)

Figure 6: Time series of $\mathrm{PM}_{2.5}$ (a) before and (b) after implementation of the law. From top to bottom are Seoul, Busan, and Daegu. 

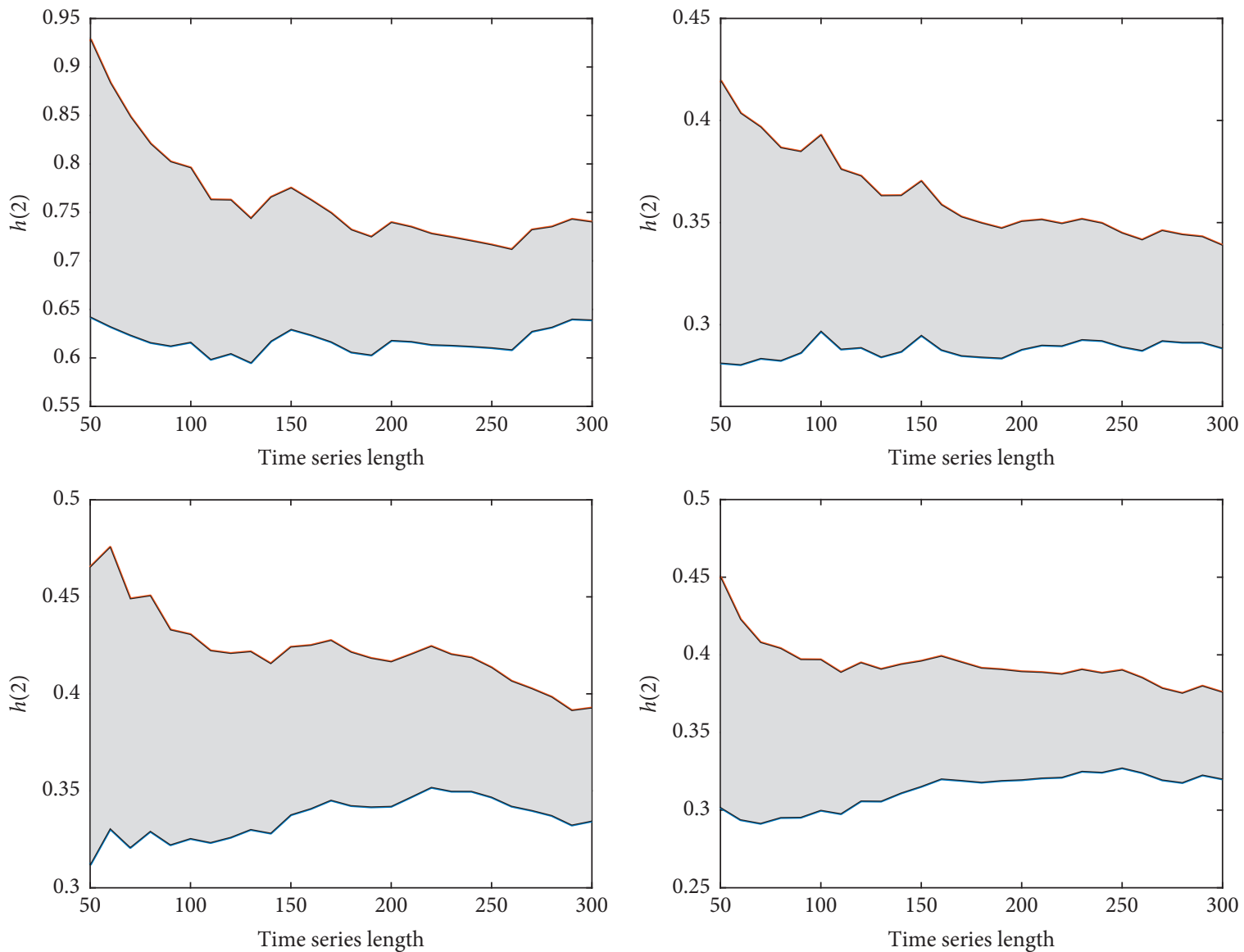

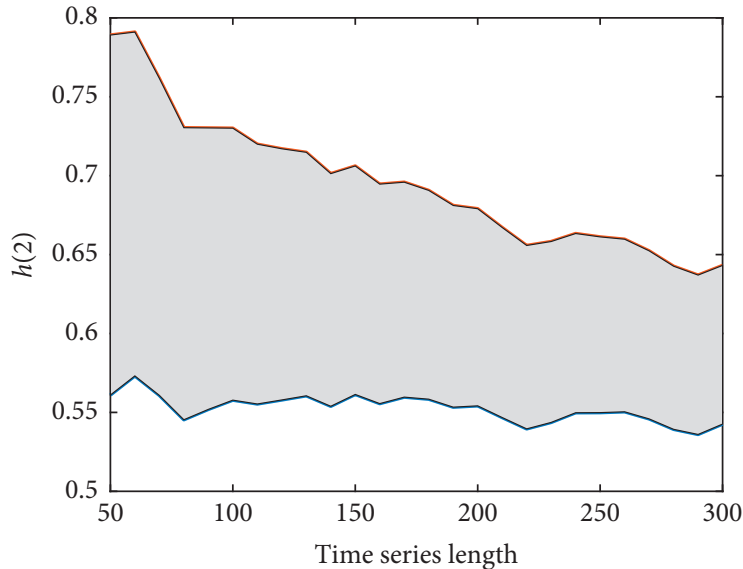

(a)

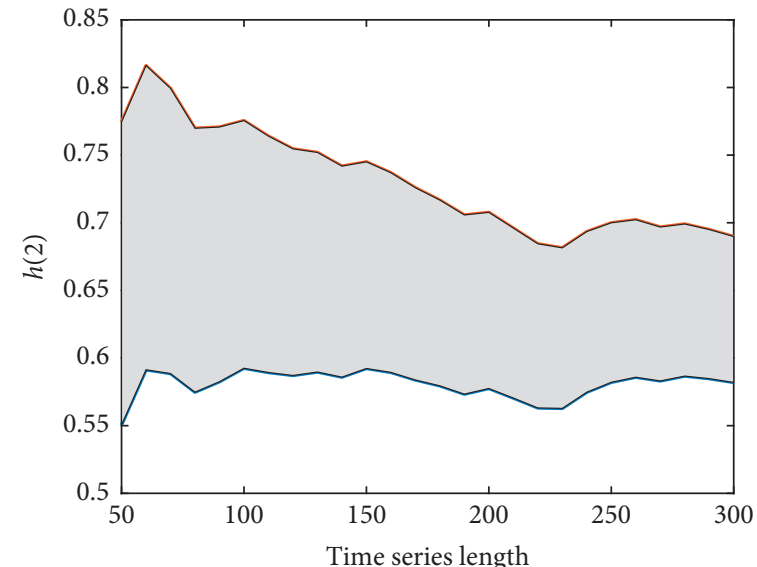

(b)

Figure 7: Confidence intervals of $h(2)$ versus the length of $P M_{2.5}$ time series (a) before and (b) after implementation of the law with confidence level by $95.0 \%$. From top to bottom are Seoul, Busan, and Daegu. 

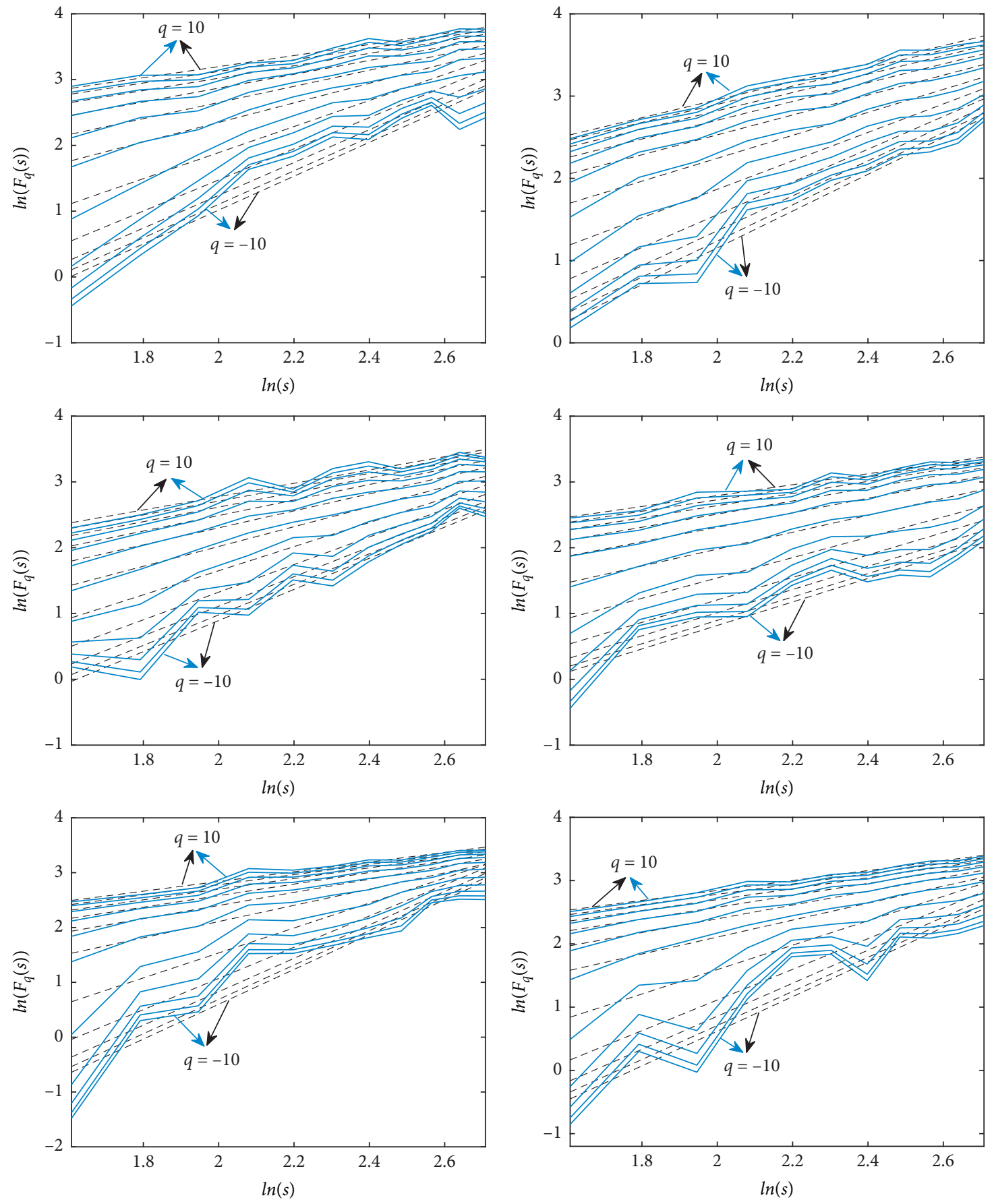

(a)

(b)

FIGURE 8: Log-log plots of the fluctuation function $F_{q}(s)$ for $\mathrm{PM}_{2.5}(\mathrm{a})$ before and (b) after implementation of the law. From top to bottom are Seoul, Busan, and Daegu. 


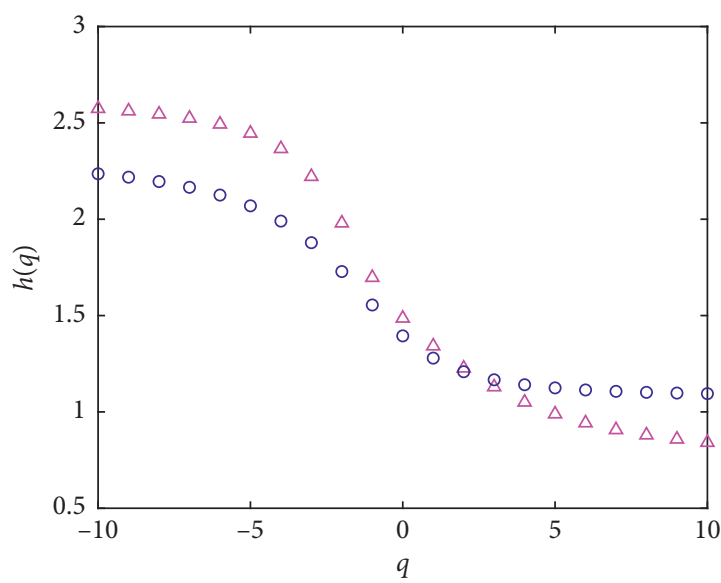

$\triangle$ Before law

- After law

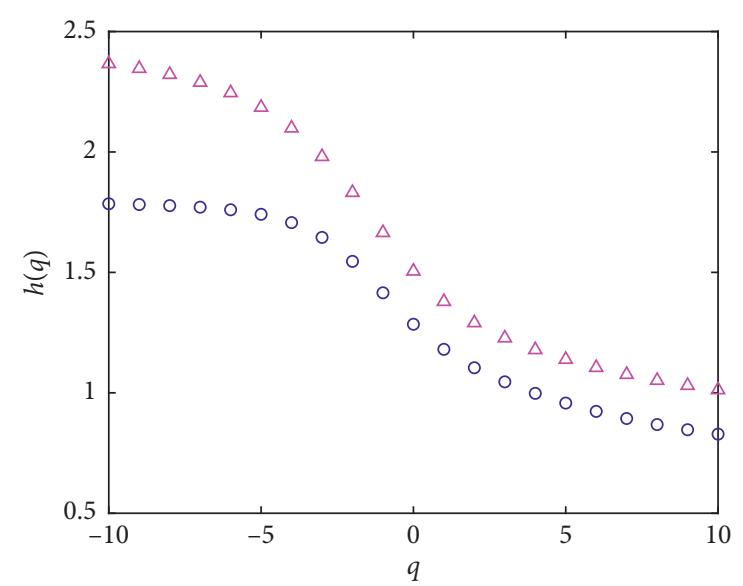

$\triangle$ Before law

- After law

(a)

(b)

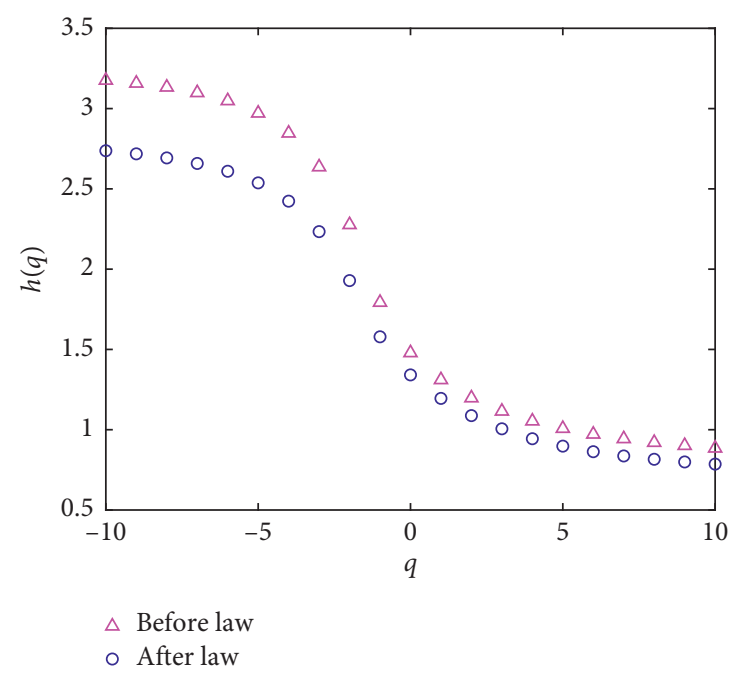

(c)

Figure 9: Hurst exponent of $\mathrm{PM}_{2.5}$ concentration of (a) Seoul, (b) Busan, and (c) Daegu.

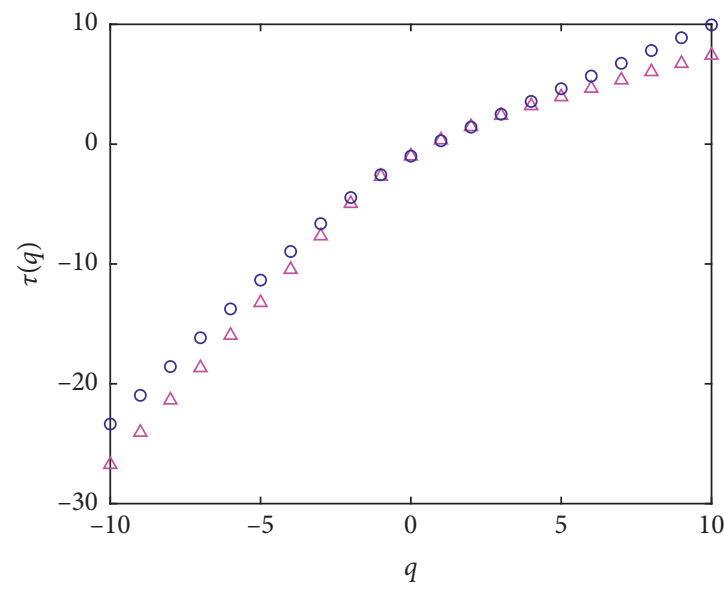

$\triangle$ Before law

- After law

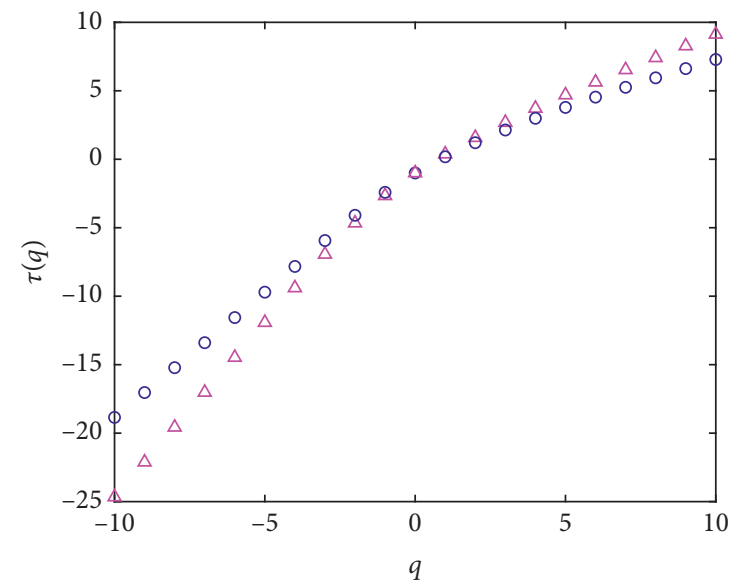

$\triangle$ Before law

- After law

(a)

(b)

Figure 10: Continued. 


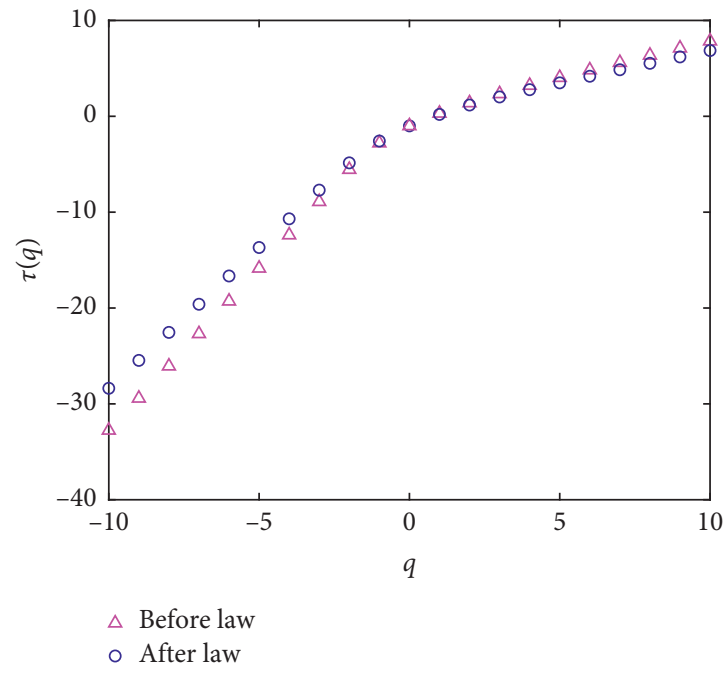

(c)

Figure 10: Renyi exponent of $\mathrm{PM}_{2.5}$ concentration of (a) Seoul, (b) Busan, and (c) Daegu.
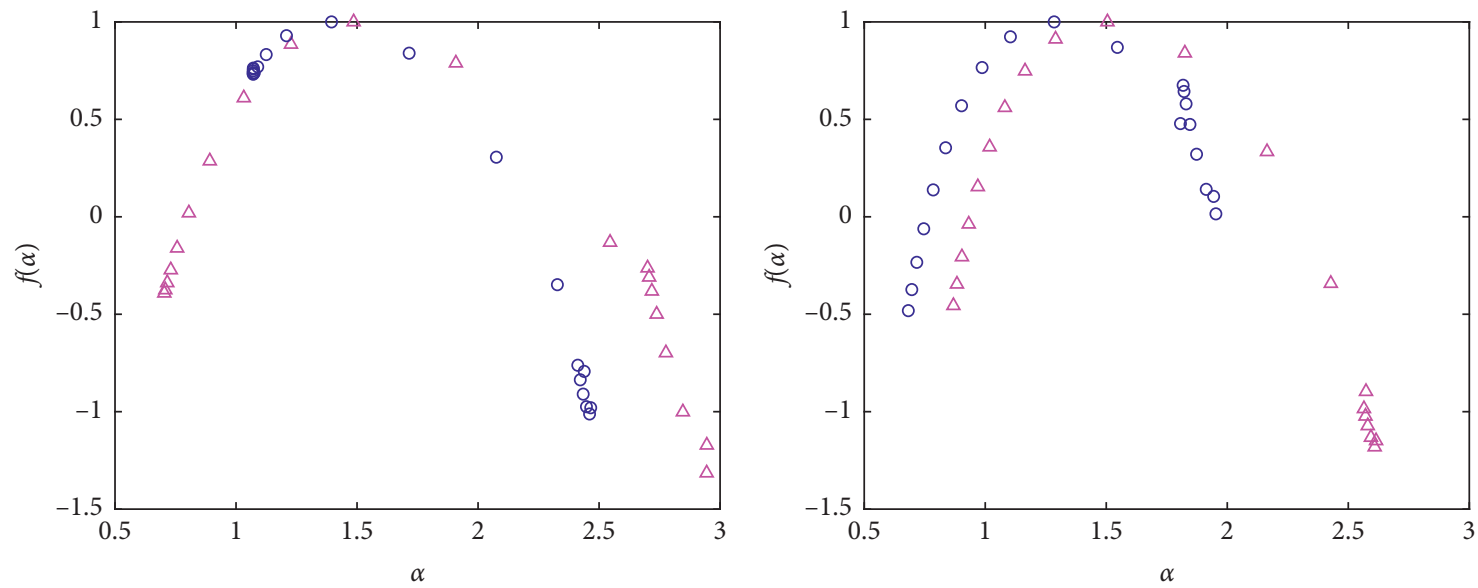
$\triangle$ Before law
$\triangle$ Before law
- After law
- After law

(a)

(b)

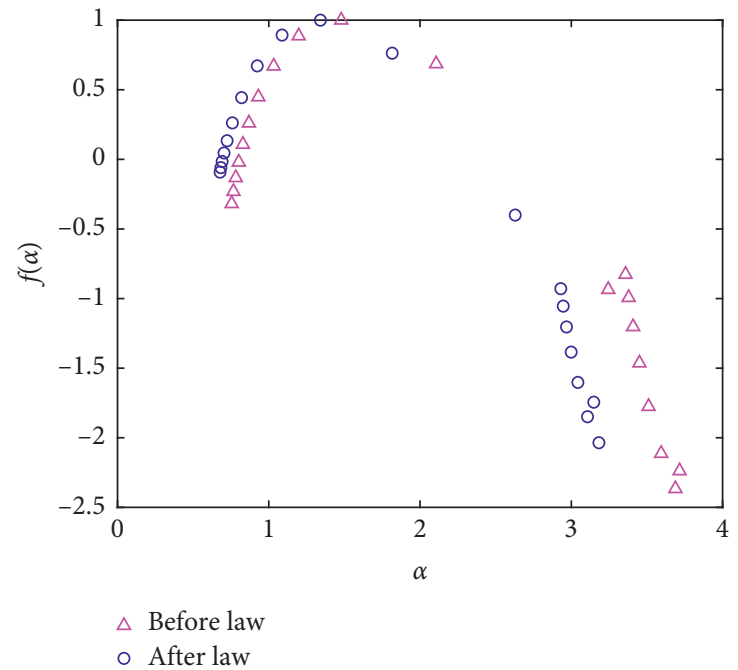

(c)

Figure 11: Holder exponent of $\mathrm{PM}_{2.5}$ concentration of (a) Seoul, (b) Busan, and (c) Daegu. The triangle and circle symbols represent before and after the law, respectively. 
TABLE 4: Multifractality for $\mathrm{PM}_{2.5}$ concentration.

\begin{tabular}{lccr}
\hline City & Multifractality & Before law & After law \\
\hline \multirow{3}{*}{ Seoul } & $h(2)$ & 1.2270 & 1.2085 \\
& $\Delta H(q)$ & 1.7329 & 1.1410 \\
& $\Delta \alpha$ & 2.2414 & 1.3953 \\
\hline \multirow{3}{*}{ Busan } & $h(2)$ & 1.2905 & 1.1041 \\
& $\Delta H(q)$ & 1.3539 & 0.9565 \\
\hline \multirow{3}{*}{ Daegu } & $\Delta \alpha$ & 1.7463 & 1.2708 \\
& $h(2)$ & 1.1975 & 1.0878 \\
& $\Delta H(q)$ & 2.2910 & 1.9516 \\
& $\Delta \alpha$ & 2.9610 & 2.5043 \\
\hline
\end{tabular}

Table 3, the conclusion we described above about the Hurst exponent and the Renyi exponent is discussed. Moreover, as shown in Figure 5, the multifractal spectra are strongly asymmetrical, and as an important indicator of fractal organization, the asymmetry coefficient, which is used to quantify the asymmetry of the multifractal spectrum, has been estimated in [37].

Based on Table 3, the multifractal features can be clearly confirmed for all time series, and it can be seen that except for spring, the Hurst exponents and multifractal spectrum widths of $\mathrm{PM}_{2.5}$ are obviously larger than those of $\mathrm{NO}_{2}$ and the multifractal degrees of $\mathrm{PM}_{2.5}$ are stronger than those of $\mathrm{NO}_{2}$.

4.2. Implications of the "Haze Special Law". In this section, we focus on the enactment of the "haze special law" and study whether the law is effective in the governance of atmospheric pollution. We select daily data from the same period described in Section 3. As we studied above, the multifractal degree of $\mathrm{PM}_{2.5}$ is stronger than that of $\mathrm{NO}_{2}$. Thus, in this section, we focus on the comparison of $\mathrm{PM}_{2.5}$ concentrations. We show the $\mathrm{PM}_{2.5}$ time series before and after the law was implemented in Seoul, Busan, and Daegu in Figure 6.

As the fluctuation statistics are of asymptotic feature, a sufficiently long-length sequence guarantees the accurate estimation of the Hurst exponent, and for a small-length sequence, the asymptotic value in the slope of $\ln \left(F_{q}(s)\right)$ versus $\ln (s)$ will be lacked [38]. As the total number of observations is selected to be 305 , to eliminate the doubt of whether the selected time series can give representative results for a multifractal analysis in the investigation, we dealt with this concern by computing confidence intervals of Hurst exponent $h(2)$ to check whether there is a difference caused by the law for all the three cities. The number of samples increased from 50 to 300 , and every additional interval is 10 . The confidence level is selected as $95.0 \%$. For each set of sample lengths, we generate the shuffled time series 1000 times, and then, the confidence interval is plotted in Figure 7.

As shown in Figure 7 and as expected, the domain size decreases with an increase in the length of the time series. However, when the length of the time series is larger than 200, the decrease in the domain size of the confidence intervals is rather slow, and of a distinct asymptotic behavior. Besides, we see that the confidence intervals do not overlap for Seoul, while for Busan $([0.34,0.39]$ before and $[0.32,0.37]$ after $)$ and Daegu $([0.55,0.64]$ before and $[0.58,0.69]$ after $)$, the confidence intervals overlap a lot. Therefore, we can conclude that there is a difference caused by the law for Seoul; however, the same conclusion is inconclusive for Busan and Daegu.

Now, we first depict the log-log plots of the fluctuation function $F_{q}(s)$ versus $q$ and $s$ for the $\mathrm{PM}_{2.5}$ time series. As illustrated in Figure 8, for all series, the fluctuation value increases linearly with $s$, indicating that a power-law behavior and long-range correlations exist in each series pair. The decreasing gradient shows that all time series have multifractal characteristics.

The generalized Hurst exponent $h(q)$, Renyi exponent $\tau(q)$, and Holder exponent $\alpha$ of the time series before and after the enactment of the "haze special law" for all the three cities are shown in Figures 9-11, respectively.

In Figure 9, it is shown that the generalized Hurst exponents $h(q)$ of $\mathrm{PM}_{2.5}$ of all three cities decrease with varied $q$, thereby showing the multifractal behaviors of these two series. We present $h$ (2) for these series in Table 4. All Hurst exponents are confirmed to be larger than 0.5 , which indicates that all the time series exhibit positive persistence. Besides, we observe that $h(2)$ before the implementation of the law is larger than after the law, implying that the fluctuations before the law have more significant persistence. Subsequently, we calculate the range of $h(q)$ for each time series and list them in Table 4 . We find that for all three cities, $\Delta H(q)$ after the law is larger, which indicates that the multifractal characteristics are stronger, and that the multifractalities of the time series before the law are more stable.

The Renyi exponents $\tau(q)$ plotted in Figure 10 are nonlinear along $q$, which provides further evidence of the existence of multifractality. We notice that the curvature of the Renyi exponents before the law are higher, which implies that the time series before the implementation of the law have stronger multifractal characteristics. All of these are consistent with the results calculated from the generalized Hurst exponents.

At last, the multifractal spectrums of these time series are examined. We depict the curves between $\alpha$ and $f(\alpha)$ in Figure 11 . We see that the multifractal spectra are not shown as points, which indicates all the time series have multifractality. Then, $\Delta \alpha$ are calculated and presented in Table 4. From Table 4 , it can be seen that $\Delta H(q)$ and $\Delta \alpha$ of the time series after the enactment of law are lower than those before 

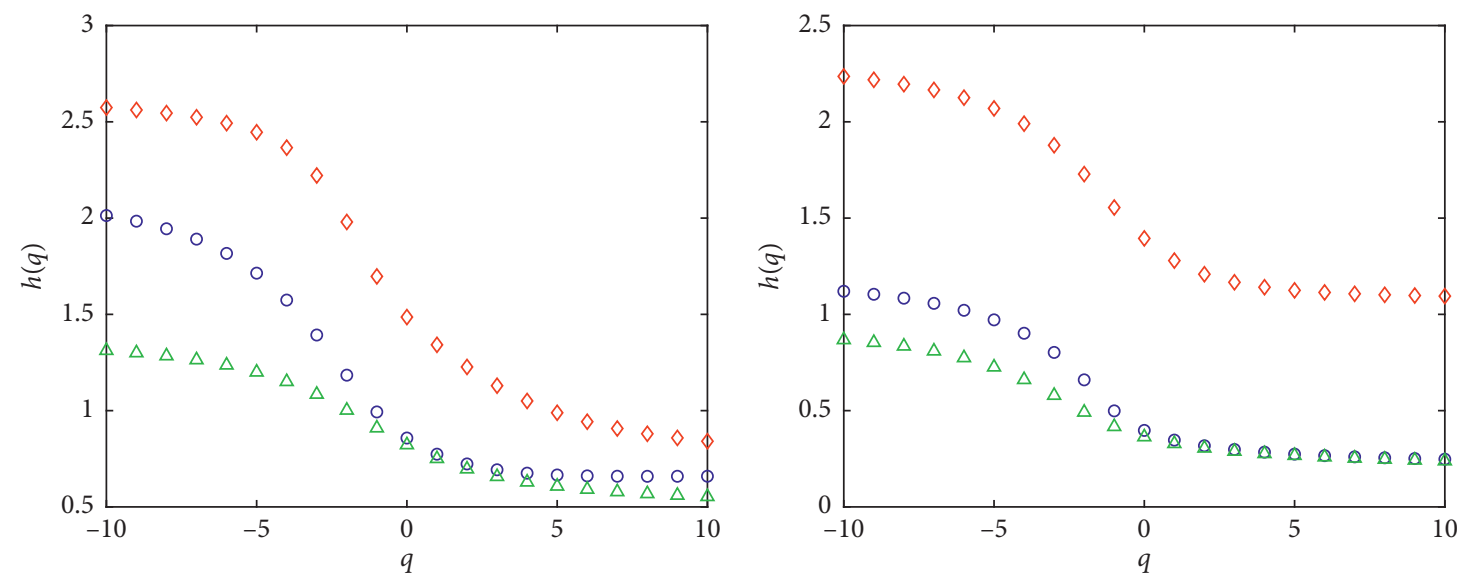

$\diamond$ Original

- Shuffled

$\triangle$ Phase-randomized

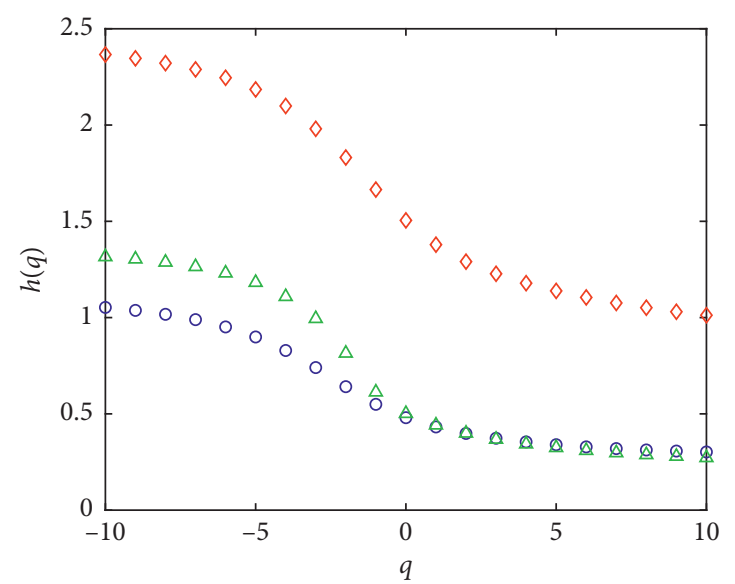

$\diamond$ Original

- Shuffled

$\triangle$ Phase-randomized

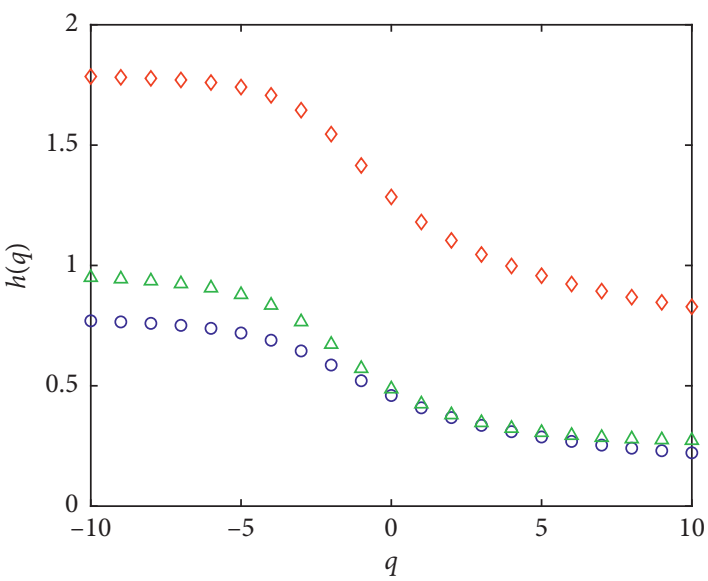

$\diamond$ Original

- Shuffled

$\triangle$ Phase-randomized

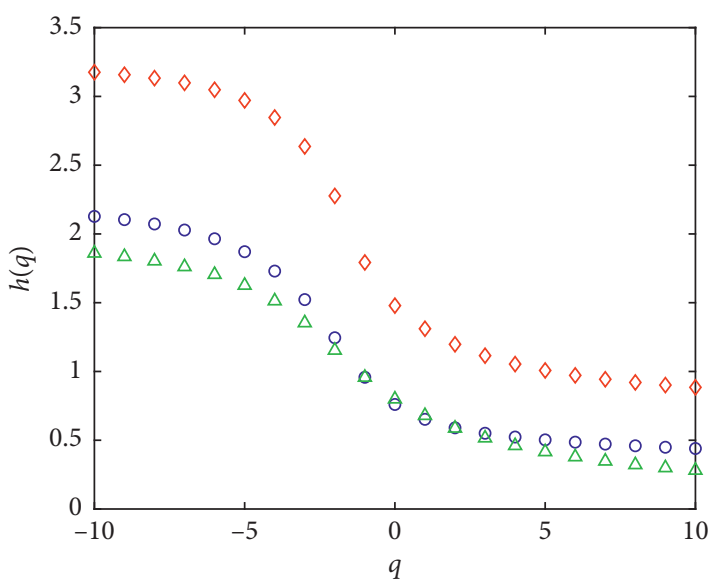
$\diamond$ Original
- Shuffled
$\triangle$ Phase-randomized

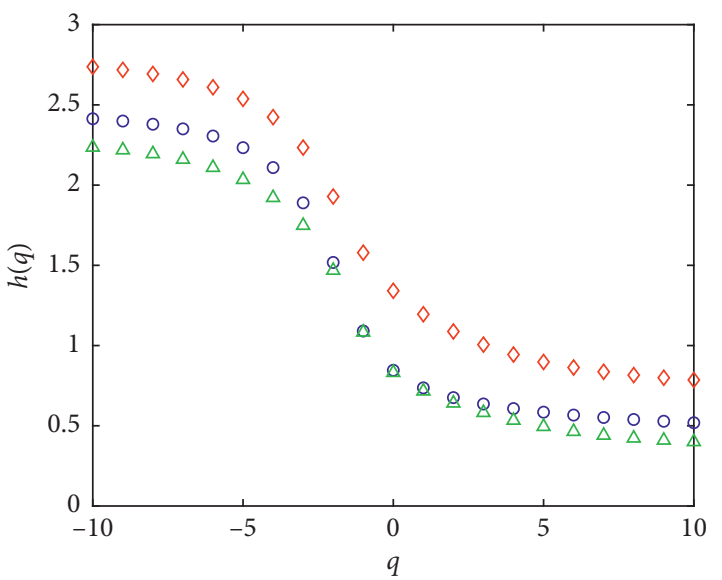

$\diamond$ Original

- Shuffled

$\triangle$ Phase-randomized
$\diamond$ Original
- Shuffled
$\triangle$ Phase-randomized

(a)

(b)

Figure 12: Hurst exponent (a) before law and (b) after law. From top to bottom are Seoul, Busan, and Daegu. 

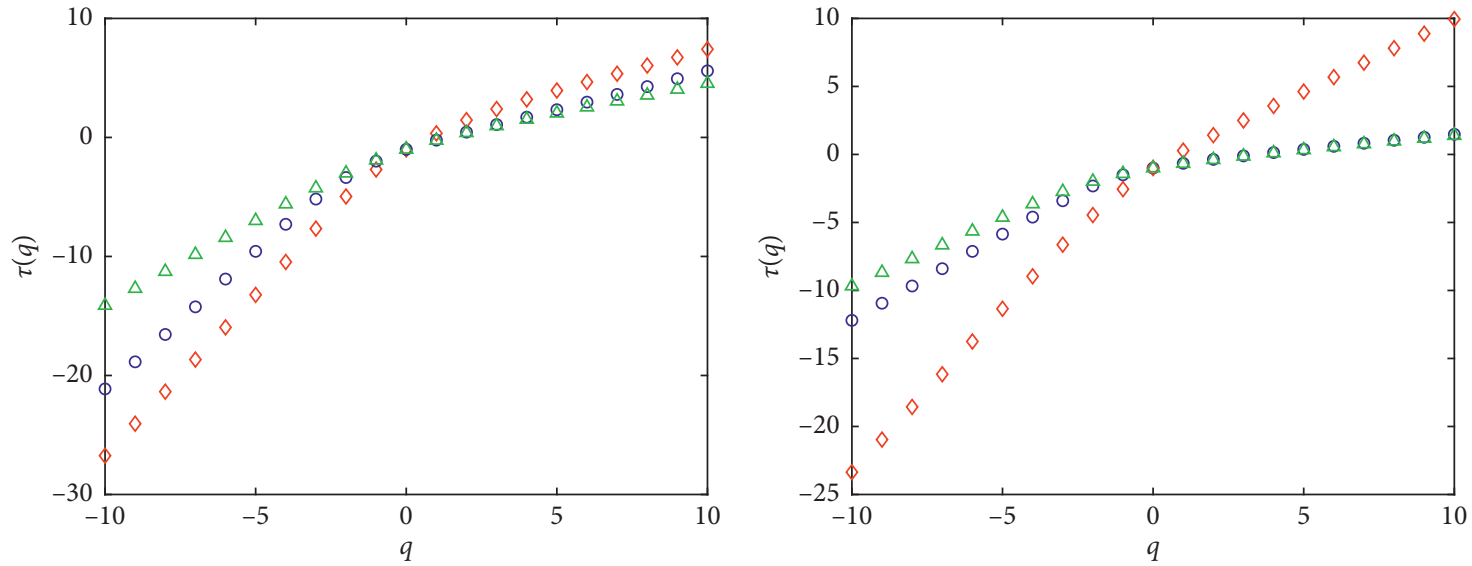

$\diamond$ Original

- Shuffled

$\triangle$ Phase-randomized

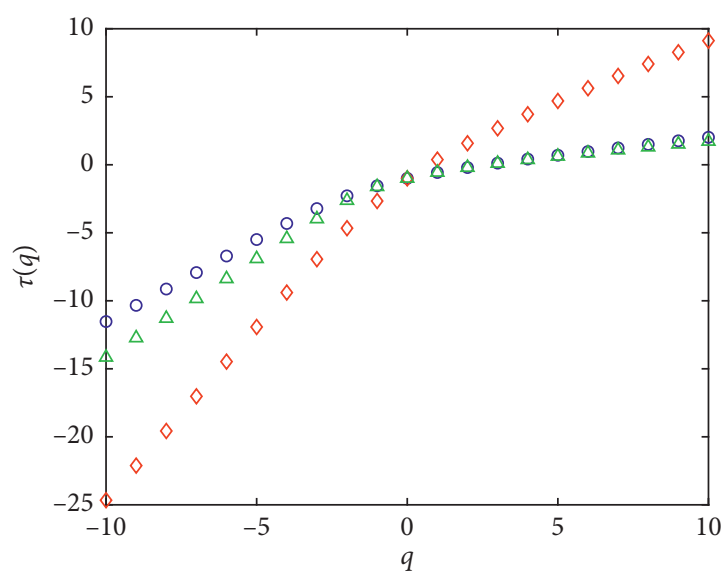
$\diamond$ Original
- Shuffled
$\triangle$ Phase-randomized

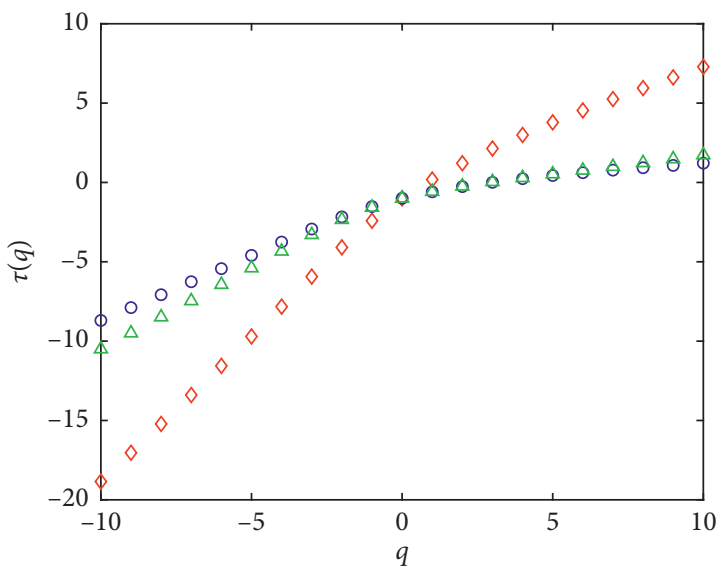

$\diamond$ Original

$\diamond$ Original

- Shuffled

$\triangle$ Phase-randomized
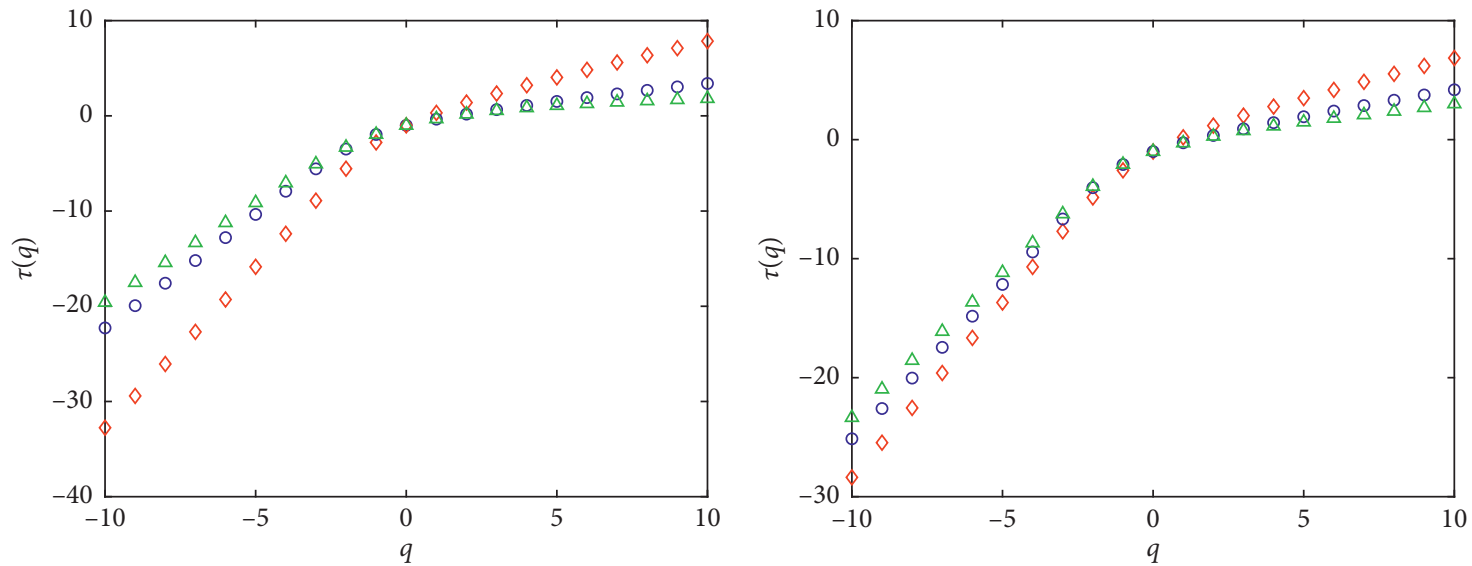

$\diamond$ Original

- Shuffled

$\triangle$ Phase-randomized
$\diamond$ Original
- Shuffled
$\triangle$ Phase-randomized

(a)

(b)

Figure 13: Renyi exponent (a) before law and (b) after law. From top to bottom are Seoul, Busan, and Daegu. 

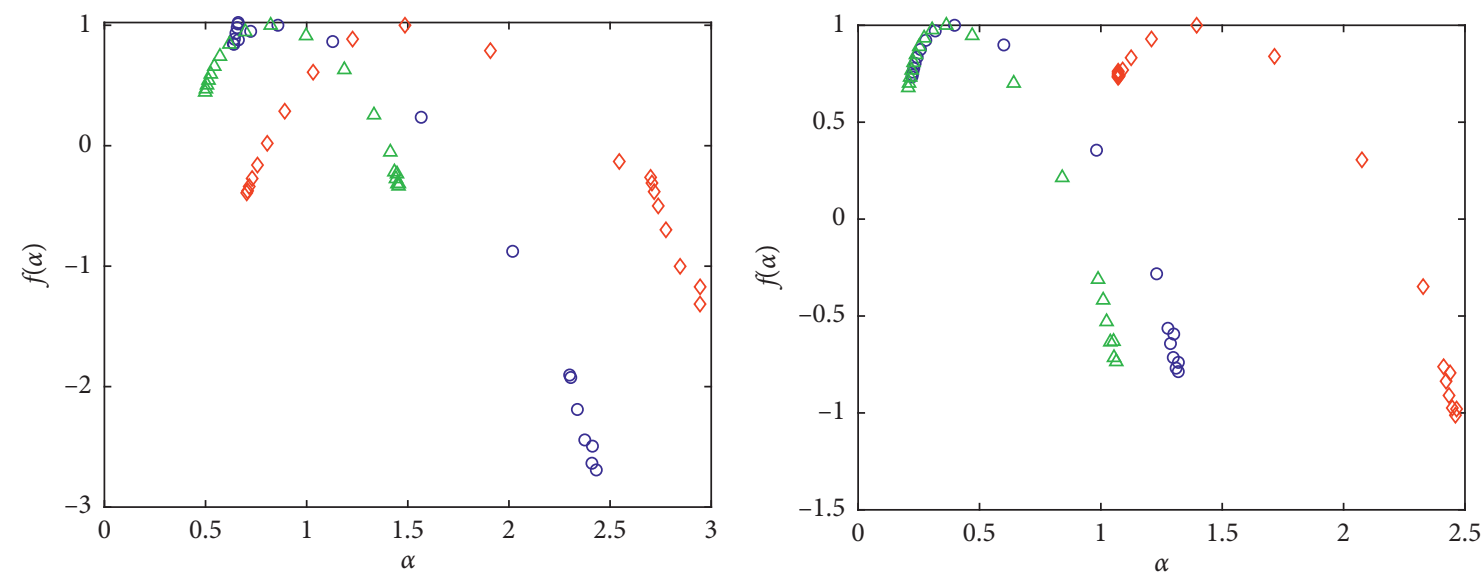

$\diamond$ Original

- Shuffled

$\triangle$ Phase-randomized

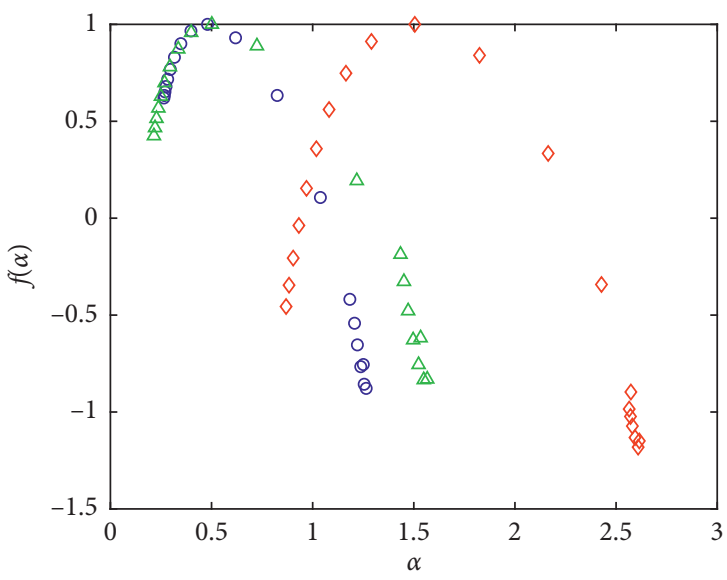

$\diamond$ Original

- Shuffled

$\Delta$ Phase-randomized

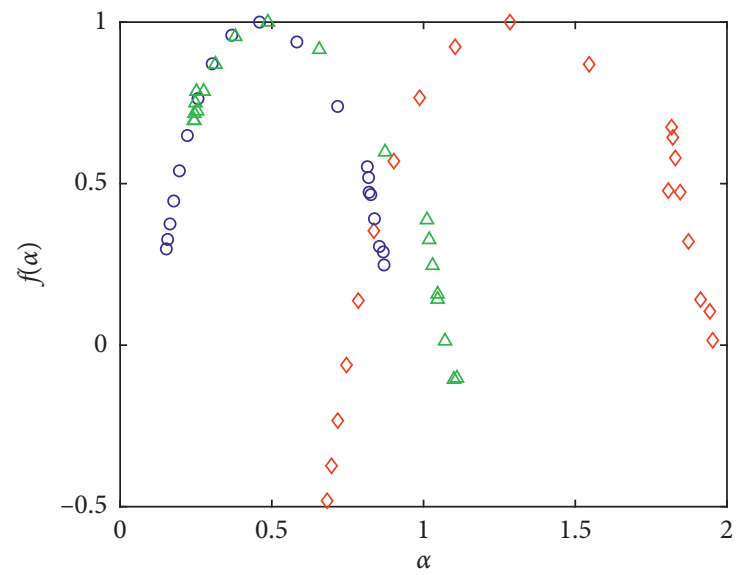

$\diamond$ Original

- Shuffled

$\triangle$ Phase-randomized

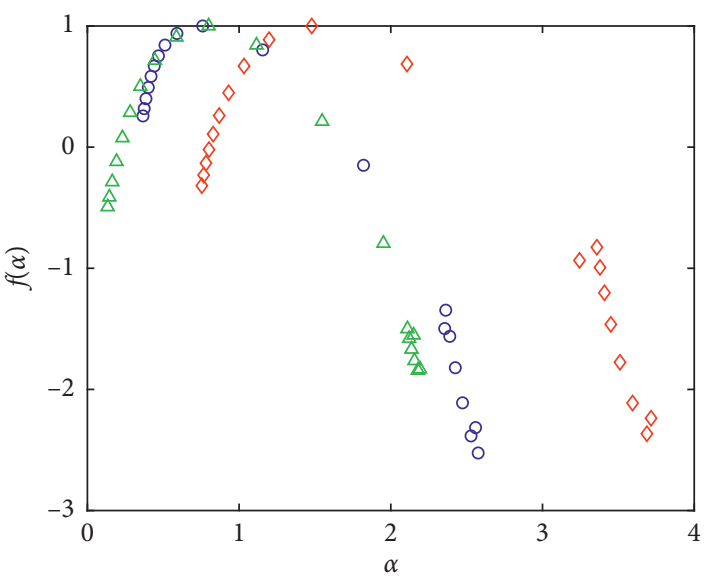

$\diamond$ Original

- Shuffled

$\triangle$ Phase-randomized

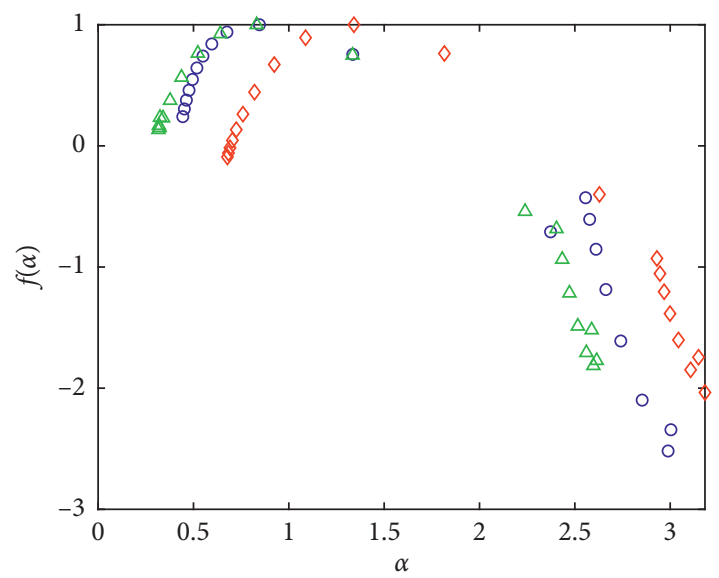

$\diamond$ Original

$\diamond$ Original

- Shuffled

- Shuffled

$\Delta$ Phase-randomized

(a)

(b)

Figure 14: Holder exponent (a) before law and (b) after law. From top to bottom are Seoul, Busan, and Daegu. 
TABle 5: Multifractality of $\mathrm{PM}_{2.5}$ time series.

\begin{tabular}{|c|c|c|c|c|c|c|}
\hline & & & $h(2)$ & $\Delta \alpha$ & LRC & FTD \\
\hline \multirow{6}{*}{ Seoul } & \multirow{3}{*}{ Before } & Original & 1.2270 & 2.2414 & \multirow{3}{*}{ No } & \multirow{3}{*}{ Yes } \\
\hline & & Shuffled & 0.7232 & 1.7946 & & \\
\hline & & Phase-randomized & 0.6965 & 0.9574 & & \\
\hline & \multirow{3}{*}{ After } & Original & 1.2085 & 1.3953 & \multirow{3}{*}{ No } & \multirow{3}{*}{ Yes } \\
\hline & & Shuffled & 0.3177 & 1.0978 & & \\
\hline & & Phase-randomized & 0.3049 & 0.8569 & & \\
\hline \multirow{6}{*}{ Busan } & \multirow{3}{*}{ Before } & Original & 1.2905 & 1.7463 & \multirow{3}{*}{ Yes } & \multirow{3}{*}{ No } \\
\hline & & Shuffled & 0.3982 & 0.9999 & & \\
\hline & & Phase-randomized & 0.3993 & 1.3512 & & \\
\hline & \multirow{3}{*}{ After } & Original & 1.1041 & 1.2708 & \multirow{3}{*}{ Yes } & \multirow{3}{*}{ No } \\
\hline & & Shuffled & 0.3678 & 0.7175 & & \\
\hline & & Phase-randomized & 0.3794 & 0.8673 & & \\
\hline \multirow{6}{*}{ Daegu } & \multirow{3}{*}{ Before } & Original & 1.1975 & 2.9610 & \multirow{4}{*}{ No } & \multirow{3}{*}{ Yes } \\
\hline & & Shuffled & 0.5901 & 2.2093 & & \\
\hline & & Phase-randomized & 0.5868 & 2.0587 & & \\
\hline & \multirow{3}{*}{ After } & Original & 1.0878 & 2.5043 & & \multirow{3}{*}{ Yes } \\
\hline & & Shuffled & 0.6756 & 2.5600 & \multirow[t]{2}{*}{ No } & \\
\hline & & Phase-randomized & 0.6407 & 2.2981 & & \\
\hline
\end{tabular}

LRC and FTD represent the long-range correlations and fat-tailed distribution, respectively.

the implementation of the law for all three cities, implying that the multifractality of the time series becomes more stable with the measures taken by the government and that the efficiency of the "haze special law" in three cities is demonstrable; this conclusion can be referred to $[16,39]$, in which it was pointed out that the decrease in multifractality means the efficiency is improved when some measures are taken. Moreover, we also notice that the efficiency of the "haze special law" in Seoul is most obvious, when compared with Busan, and in last place is Daegu. Interestingly, the order is the same as the scale and prosperity of the cities. We can therefore conclude that the law has a higher effect on a larger city.

4.3. Sources of Multifractal Features. The two universally acknowledged sources of multifractality are long-range correlations and a fat-tailed distribution [7, 40]. Now, we investigate the major source of multifractality of the $\mathrm{PM}_{2.5}$ concentration series. To check the contribution of longrange correlations and fat-tailed distribution quantitatively, we shuffle and phase-randomize the time series.

Subsequently, we calculate the Hurst exponent $h(q)$, the Renyi exponent $\tau(q)$, and the Holder exponent $\Delta \alpha$ of the original, shuffled, and phase-randomized time series of the three cities. As shown in Figures 12-14, all the time series are strongly multifractal. From Table 5 , all $h(2)$ of the original series are larger than those of the shuffled and phase-randomized time series, which indicates that the persistence has been moved after shuffling and phase-randomization. Moreover, the original series of all three cities has the greatest spectrum width $\Delta \alpha$, while the multifractality decreased after shuffling and phase-randomizing the series. The findings can also be confirmed in Figures 12-14.

To examine the main source of multifractality, the first and third rows of Figure 14 show that the multifractal spectra of phase-randomized series are the narrowest ones, which means that the main source of multifractality of the series before and after the law in Seoul and Daegu are the fattailed distributions. The second row in Figure 14 shows that the multifractal spectrum of the shuffled series is the narrowest, which implies that the long-range correlation results in multifractality of the series before and after implementation of the law in Busan.

\section{Conclusions}

In this study, we examined the multifractal characteristics of $\mathrm{PM}_{2.5}$ and $\mathrm{NO}_{2}$ time series of all seasons. We determined that multifractality existed in each season, and the multifractal property of $\mathrm{PM}_{2.5}$ was stronger than that of $\mathrm{NO}_{2}$ in each season. We also validated the effectiveness of the "haze special law," which was implemented to improve the governance of air pollution in South Korea. We checked whether there is a difference caused by the law for these cities and calculated confidence intervals of Hurst exponent $h(2)$. The results showed that the confidence intervals do not overlap for Seoul, while the confidence intervals overlap a lot for Busan and Daegu, indicating that there is a difference caused by the law for Seoul; however, the same conclusion is inconclusive for Busan and Daegu. By comparing the Hurst exponent, Renyi exponent, and Holder exponent, the time series of the $\mathrm{PM}_{2.5}$ concentration before the implementation of the law was found to have a higher multifractal degree, which decreased after the enactment of the law. This phenomenon reflected the fact that the law has played a role in improving the efficiency of air pollution control in South Korea. We also concluded that the effect of the law will be more significant in a larger city. To explore the major causes of multifractality, we shuffled and phase-randomized the original series of $\mathrm{PM}_{2.5}$. By analyzing the width of the multifractal spectrum $\Delta \alpha$, the results showed that the fattailed distribution contributed to the multifractality of both times series before and after the implementation of the "haze special law" in Seoul and Daegu, whereas long-range correlations resulted in the multifractality of the series before and after the implementation of the law in Busan. We concluded that the implementation of the law was very successful and effective for the improvement of $\mathrm{PM}_{2.5}$ levels. Therefore, we believe that the "haze special law" is a possible cause for the change in API in South Korea.

\section{Data Availability}

The data will be available upon request with the corresponding author.

\section{Conflicts of Interest}

The authors declare that there are no conflicts of interest regarding the publication of this article.

\section{Acknowledgments}

The first author (Jian Wang) was supported by the China Scholarship Council (201808260026). J. S. Kim expresses gratitude for the support from the BK21 PLUS program. The 
corresponding author Wei Shao thanks Professor Darae Jeong for helpful discussion.

\section{References}

[1] G. Shaddick and J. Wakefield, "Modelling daily multivariate pollutant data at multiple sites," Journal of the Royal Statistical Society: Series C (Applied Statistics), vol. 51, no. 3, pp. 351-372, 2002.

[2] M. O'Dwyer, Air Quality in Ireland 2010: Key Indicators of Ambient Air Quality, EPA, Wexford, Ireland, 2011.

[3] A. Challoner and L. Gill, "Indoor/outdoor air pollution relationships in ten commercial buildings: $\mathrm{PM}_{2.5}$ and $\mathrm{NO}_{2}$," Building and Environment, vol. 80, pp. 159-173, 2014.

[4] M. Hazenkamp-von Arx, T. Gotschi, U. Ackermann-Liebrich et al., " $\mathrm{PM}_{2.5}$ and $\mathrm{NO}_{2}$ assessment in 21 European study centres of ECRHS II: annual means and seasonal differences," Atmospheric Environment, vol. 38, no. 13, pp. 1943-1953, 2004.

[5] H. K. Lai, L. Bayer-Oglesby, R. Colvile et al., "Determinants of indoor air concentrations of $\mathrm{PM}_{2.5}$, black smoke and $\mathrm{NO}_{2}$ in six European cities (EXPOLIS study)," Atmospheric Environment, vol. 40, no. 7, pp. 1299-1313, 2006.

[6] K. de Hoogh, J. Gulliver, A. V. Donkelaar et al., "Development of West-European $\mathrm{PM}_{2.5}$ and $\mathrm{NO}_{2}$ land use regression models incorporating satellite-derived and chemical transport modelling data," Environmental Research, vol. 151, pp. 1-10, 2016.

[7] S. Drożdż, J. Kwapień, P. Oświecimka, and R. Rak, "Quantitative features of multifractal subtleties in time series," EPL (Europhysics Letters), vol. 88, no. 6, p. 60003, 2010.

[8] R. J. Buonocore, T. Aste, and T. Di Matteo, "Measuring multiscaling in financial time-series," Chaos, Solitons \& Fractals, vol. 88, pp. 38-47, 2016.

[9] P. Oświecimka, S. Drożdż, J. Kwapień, and A. Z. Górski, "Fractals, log-periodicity and financial crashes," Acta Physica Polonica A, vol. 117, no. 4, pp. 637-639, 2010.

[10] B. B. Mandelbrot and N. Goldenfeld, "Fractals and scaling in finance: discontinuity, concentration, risk," Physics Today, vol. 51, no. 8, pp. 59-60, 1998.

[11] S. Drożdż, R. Kowalski, P. Oświecimka, R. Rak, and R. Gebarowski, "Dynamical variety of shapes in financial multifractality," Complexity, vol. 2018, Article ID 7015721, 13 pages, 2018.

[12] S. Lahmiri, "Multifractal analysis of Moroccan family business stock returns," Physica A: Statistical Mechanics and Its Applications, vol. 486, pp. 183-191, 2017.

[13] X. Zhao, P. Shang, and Q. Jin, "Multifractal detrended crosscorrelation analysis of Chinese stock markets based on time delay," Fractals, vol. 19, no. 03, pp. 329-338, 2011.

[14] W. Shao and J. Wang, "Does the "ice-breaking" of South and North Korea affect the South Korean financial market?" Chaos, Solitons \& Fractals, vol. 132, Article ID 109564, 2020.

[15] D.-H. Wang, X.-W. Yu, and Y.-Y. Suo, "Statistical properties of the yuan exchange rate index," Physica A: Statistical Mechanics and Its Applications, vol. 391, no. 12, pp. 3503-3512, 2012.

[16] Y. Ning, Y. Wang, and C.-W. Su, "How did China's foreign exchange reform affect the efficiency of foreign exchange market?" Physica A: Statistical Mechanics and Its Applications, vol. 483, pp. 219-226, 2017.

[17] S. Lahmiri and S. Bekiros, "Chaos, randomness and multifractality in bitcoin market," Chaos, Solitons \& Fractals, vol. 106, pp. 28-34, 2018.
[18] P. Manimaran and A. C. Narayana, "Multifractal detrended cross-correlation analysis on air pollutants of University of Hyderabad Campus, India," Physica A: Statistical Mechanics and Its Applications, vol. 502, pp. 228-235, 2018.

[19] L. Zhao, W. Li, C. Yang, J. Han, Z. Su, and Y. Zou, "Multifractality and network analysis of phase transition," PLoS One, vol. 12, Article ID e0170467, 2017.

[20] N. Kalamaras, K. Philippopoulos, D. Deligiorgi, C. G. Tzanis, and G. Karvounis, "Multifractal scaling properties of daily air temperature time series," Chaos, Solitons \& Fractals, vol. 98, pp. 38-43, 2017.

[21] J. Li, C. Chen, Q. Yao et al., "The effect of circadian rhythm on the correlation and multifractality of heart rate signals during exercise," Physica A: Statistical Mechanics and Its Applications, vol. 509, pp. 1207-1213, 2018.

[22] P. Castiglioni, D. Lazzeroni, P. Coruzzi, and A. Faini, "Multifractal-multiscale analysis of cardiovascular signals: a DFA-based characterization of blood pressure and heart-rate complexity by gender," Complexity, vol. 2018, Article ID 4801924, 14 pages, 2018.

[23] W. Shi, R.-B. Zou, F. Wang, and L. Su, "A new image segmentation method based on multifractal detrended moving average analysis," Physica A: Statistical Mechanics and Its Applications, vol. 432, pp. 197-205, 2015.

[24] F. Wang, Q. Fan, and H. E. Stanley, "Multiscale multifractal detrended-fluctuation analysis of two-dimensional surfaces," Physical Review E, vol. 93, Article ID 042213, 2016.

[25] X. Li, M. Zheng, J. Pu et al., "Identification of abnormally expressed lncrnas induced by $\mathrm{PM}_{2.5}$ in human bronchial epithelial cells," Bioscience Reports, vol. 38, no. 5, Article ID BSR20171577, 2018.

[26] K. Shi, C. Liu, and Y. Huang, "Multifractal processes and selforganized criticality of $\mathrm{PM}_{2.5}$ during a typical haze period in Chengdu, China," Aerosol and Air Quality Research, vol. 15, no. 3, pp. 926-934, 2015.

[27] C. Zhang, Z. Ni, and L. Ni, "Multifractal detrended crosscorrelation analysis between $\mathrm{PM}_{2.5}$ and meteorological factors," Physica A: Statistical Mechanics and Its Applications, vol. 438, pp. 114-123, 2015.

[28] C. Zhang, X. Wang, S. Chen, L. Zou, X. Zhang, and C. Tang, "A study on daily $\mathrm{PM}_{2.5}$ concentrations in Hong Kong using the EMD-based MFDFA method," Physica A: Statistical Mechanics and Its Applications, vol. 530, p. 121182, 2019.

[29] H.-D. He, "Multifractal analysis of interactive patterns between meteorological factors and pollutants in urban and rural areas," Atmospheric Environment, vol. 149, pp. 47-54, 2017.

[30] J. W. Kantelhardt, S. A. Zschiegner, E. Koscielny-Bunde, S. Havlin, A. Bunde, and H. E. Stanley, "Multifractal detrended fluctuation analysis of nonstationary time series," Physica A: Statistical Mechanics and Its Applications, vol. 316, no. 1-4, pp. 87-114, 2002.

[31] L. Zunino, B. M. Tabak, A. Figliola, D. G. Pérez, M. Garavaglia, and O. A. Rosso, "A multifractal approach for stock market inefficiency," Physica A: Statistical Mechanics and Its Applications, vol. 387, no. 26, pp. 6558-6566, 2008.

[32] L. Zunino, A. Figliola, B. M. Tabak, D. G. Pérez, M. Garavaglia, and O. A. Rosso, "Multifractal structure in Latin-American market indices," Chaos, Solitons \& Fractals, vol. 41, no. 5, pp. 2331-2340, 2009.

[33] B. Lashermes, P. Abry, and P. Chainais, "New insights into the estimation of scaling exponents," International Journal of Wavelets, Multiresolution and Information Processing, vol. 2, no. 4, pp. 497-523, 2004. 
[34] E. A. F. Ihlen, "Introduction to multifractal detrended fluctuation analysis in Matlab," Frontiers in Physiology, vol. 3, p. 141, 2012.

[35] L. Jiang, X. Zhao, N. Li, F. Li, and Z. Guo, "Different multifractal scaling of the $0 \mathrm{~cm}$ average ground surface temperature of four representative weather stations over China," Advances in Meteorology, vol. 2013, Article ID 341934, 8 pages, 2013.

[36] P. C. Ivanov, L. A. N. Amaral, A. L. Goldberger et al., "Multifractality in human heartbeat dynamics," Nature, vol. 399, no. 6735, pp. 461-465, 1999.

[37] S. Drożdż and P. Oświecimka, "Detecting and interpreting distortions in hierarchical organization of complex time series," Physical Review E, vol. 91, Article ID 030902, 2015.

[38] C. Ibarra-Valdez, J. Alvarez, and J. Alvarez-Ramirez, "Randomness confidence bands of fractal scaling exponents for financial price returns," Chaos, Solitons \& Fractals, vol. 83, pp. 119-124, 2016.

[39] D. Stosić, D. Stosić, T. Stosić, and H. E. Stanley, "Multifractal analysis of managed and independent float exchange rates," Physica A: Statistical Mechanics and its Applications, vol. 428, pp. 13-18, 2015.

[40] K. Matia, Y. Ashkenazy, and H. E. Stanley, "Multifractal properties of price fluctuations of stocks and commodities," Europhysics Letters (EPL), vol. 61, no. 3, pp. 422-428, 2003. 